\title{
Combined use of volume radar observations and high-resolution numerical weather predictions to estimate precipitation at the ground: methodology and proof of concept
}

\author{
Tony Le Bastard ${ }^{1}$, Olivier Caumont ${ }^{2}$, Nicolas Gaussiat ${ }^{1}$, and Fatima Karbou ${ }^{3}$ \\ ${ }^{1}$ DSO-CMR, Météo-France, Toulouse, France \\ ${ }^{2}$ CNRM, Université de Toulouse, Météo-France, CNRS, Toulouse, France \\ ${ }^{3}$ CNRM-CEN, UMR 3589, Météo-France, CNRS, Saint-Martin-d'Hères, France
}

Correspondence: Tony Le Bastard (tony.lebastard@meteo.fr)

Received: 18 April 2019 - Discussion started: 17 May 2019

Revised: 21 August 2019 - Accepted: 16 September 2019 - Published: 25 October 2019

\begin{abstract}
The extrapolation of the precipitation to the ground from radar reflectivities measured at the beam altitude is one of the most delicate phases of radar data processing for producing quantitative precipitation estimations (QPEs) and remains a major scientific issue. In many operational meteorological services such as Météo-France, a vertical profile of reflectivity (VPR) correction is uniformly applied over a large part or the entire radar domain. This method is computationally efficient, and the overall bias induced by the bright band is most of the time well corrected. However, this way of proceeding is questionable in situations with high spatial and vertical variability of precipitation (during the passage of a cold front or in a complex terrain, for example).
\end{abstract}

This study initiates from two statements: first, radars provide information on precipitation with a high spatio-temporal resolution but still require VPR corrections to extrapolate rain rates at the ground level. Second, the horizontal resolution of some numerical weather prediction (NWP) models is now comparable with the radar one, and their dynamical core and microphysics schemes allow the production of realistic simulations of VPRs.

The present paper proposes a new approach to assess surface rainfall from radar reflectivity aloft by exploiting simulated VPRs and rainfall forecasts from the high-resolution NWP model AROME-NWC. To our knowledge, this is the first time that simulated precipitation profiles from an NWP model are used to derive radar QPEs.

The implementation of the new method on two stratiform situations provided significant improvements on the hourly and $6 \mathrm{~h}$ accumulations compared to the operational QPEs, showing the relevance of this new approach.

\section{Introduction}

Precise quantitative precipitation estimates (QPEs) are critical for many applications including nowcasting, hydrology and flood forecasts. For instance, high-resolution QPEs are necessary to correctly predict the occurrence and intensity of heavy rainfall events and flash floods. Operational rain gauges can provide accurate measurements of the rainfall, but the operational networks are generally too sparse to capture the high spatial and temporal variability of precipitation, especially over complex terrain.

Weather radars provide spatially continuous precipitation estimates at very high spatial and temporal resolutions, thus filling the gaps in in situ observation networks. However, the radar does not provide direct estimates of precipitation but rather an indirect measure which is the backscattered signal of hydrometeors in the atmosphere. Hydrometeors may be liquid or solid or a mixture of two states and can precipitate to the ground in the form of rain or snow depending on several factors. The estimation of precipitation by radar is therefore subject to several sources of error that need to be understood and evaluated (Zawadzki, 1984; Joss and Lee, 1995; Dinku et al., 2002; Villarini and Krajewski, 2010). 
These errors are of three kinds: (i) measurement errors of the radar moments $\left(Z, Z_{\mathrm{dr}}, \phi_{\mathrm{dp}}\right)$, (ii) conversion errors in the quantitative precipitation estimation of the precipitation from the radar moments and (iii) extrapolation errors in the determination of the precipitation falling at the ground from the estimations obtained at beam heights. In recent years, significant progress has been made to reduce the first two types of errors by better controlling the quality of the polarimetric parameters (calibration of $Z$ and $Z_{\mathrm{dr}}$, adaptive smoothing of $\phi_{\mathrm{dp}}$, attenuation correction) (Bringi et al., 2001; Gourley et al., 2009; Yu et al., 2018) and by combining the polarimetric moments to estimate the precipitation with minimal uncertainty (Ryzhkov et al., 2005; Tabary et al., 2011; Figueras i Ventura et al., 2012). However, the final step of estimating the precipitation at the ground remains a major challenge in particular in mountainous regions where lower beams can be partially or totally blocked (Creutin et al., 1997; Smith, 1998).

Many national weather services have implemented a vertical profile of reflectivity (VPR) correction that either uses a climatological profile obtained from a large number of radar observations over a period of time (Andrieu and Creutin, 1995; Vignal et al., 1999; Borga et al., 2000; Seo et al., 2000; Germann and Joss, 2002; Kirstetter et al., 2010) or uses an idealised profile adjusted in real time (Kitchen et al., 1994; Tabary, 2007) with a pixel-wise approach or not. In both correction methods, the VPR can only be retrieved to represent the volume of atmosphere sampled by the radar and thus cannot provide information on the vertical structure of the precipitation in shielded areas. As a consequence, any evaporation or enhancement of precipitation occurring below the lowest usable beam is missed and can lead in turn to an overor an underestimation of the precipitation at the surface (Gori and Joss, 1980; Hu and Srivastava, 1995; Li and Srivastava, 2001).

Bauer et al. (2015) suggested that high-resolution numerical weather prediction (NWP) models could bring useful information about the vertical structure of the precipitation which could help to address the shortcomings of radar measurements. Thus, they tried to directly retrieve QPEs from NWP model simulations (WRF) including radar data assimilation. But the developed method could not compete with observation-based QPE methods in part because of the weaknesses of the assimilation system and the model spin-up. So far the use of simulated data from NWP for producing radarbased QPE has generally been limited to the freezing level height for determining the top of the melting layer (Kitchen et al., 1994; Tabary, 2007).

More recently, some attempts to closely exploit NWP outputs have been done to assess the VPR shape in the lower levels. For instance, Georgiou et al. (2010) have proposed a parameterised orographic enhancement term to represent the seeder-feeder mechanism occurring over hills and small mountains (Purdy et al., 2005) that can be added to VPR correction. More recently, Martinaitis et al. (2018) have pro- posed a real-time evaporation correction scheme using environmental temperature and humidity from an NWP model.

Previous studies have shown that synthetic yet realistic radar observations can be obtained by applying a radar simulator to model outputs (Caumont et al., 2006; Jung et al., 2008; Pfeifer et al., 2008; Ryzhkov et al., 2011; Wolfensberger and Berne, 2018). The VPR estimation and correction is a major step in radar data processing that determines the quality of radar precipitation that would be observed at the ground. In this paper we propose a new method that allows the estimation of VPR profiles in good coherence with meteorological and radar observation conditions. We rely on predicted profiles of precipitation of the French high-resolution NWP model AROME-NWC (Auger et al., 2015), which are directly used together with the observed volume radar polarimetric parameters to determine the most realistic VPR over a particular location and produce a better estimate of the precipitation at the ground. The operational radar data processing for producing radar QPEs and the radar simulations are presented in the first section. Section 2 is dedicated to the presentation of the new QPE method. In Sect. 3, the benefits of the new method are illustrated and quantified on two particular case studies.

\section{Data and tools}

\subsection{Operational radar QPE}

The French metropolitan radar network has a total of 31 Doppler radars (5 S band, $20 \mathrm{C}$ band, and $6 \mathrm{X}$ band). All except two radars are polarimetric and configured to transmit $2 \mu$ s pulses in triple pulse repetition time mode (Tabary et al., 2006). The radar acquisition software samples the reflectivity and polarimetric parameters at the resolution of $240 \mathrm{~m} \times 0.5^{\circ}$ (polar grid) up to a maximum range of $255 \mathrm{~km}$. Radar volumes are produced every $5 \mathrm{~min}$ and are made of three to five low-elevation scans (between 0 and $3^{\circ}$ ) repeated every $5 \mathrm{~min}$ and two to three high-elevation scans (between 3 and $15^{\circ}$ ) repeated every $15 \mathrm{~min}$.

The centralised processing platform located in Toulouse ingests the raw elevation scans received from the radars and applies corrections for partial beam blockages, gas attenuation and radome attenuation (at the $\mathrm{X}$ band only) to the noisethresholded reflectivity data. The processing chain uses polarimetric variables (Figueras i Ventura and Tabary, 2013) to identify non-meteorological echoes and also corrects for the attenuation of the precipitation. Finally, the polar cells are projected on a regular Cartesian grid of $1 \mathrm{~km} \times 1 \mathrm{~km}$. All the scans are synchronised to the end of the volume scan time window using a $32 \mathrm{~km} \times 32 \mathrm{~km}$ advection field. This advection field is deduced from the two latest composite reflectivity fields through the search of the advection vectors that minimises the differences between the current composite and the advected previous one. 
Once the scan processing is complete, a VPR correction is applied to each elevation scan to produce an estimate of the reflectivity at the surface. The operational VPR correction (Tabary, 2007) uses an idealised VPR represented by four parameters (Fig. 1): the freezing level height (FLH), the decreasing rate (DR) of reflectivity above, the bright-band thickness (BBT) and its amplitude (BBP). A new idealised VPR profile is inferred every radar cycle $(5 \mathrm{~min})$ using the ratios of the hourly rain rate accumulations gathered at different elevation angles and distances from the radar. By varying the four parameters within predefined ranges $( \pm 200 \mathrm{~m}$ for FLH; 1 to 6 for BBP; 200 to $800 \mathrm{~m}$ for BBT; -1.5 to $-6 \mathrm{~dB} \mathrm{~km}^{-1}$ for DR), 288 ratio profiles of rain rate (deduced from the Marshall-Palmer relationship $Z=200 R^{1.6}$ ) are built and compared to the observed radar rain rate accumulation ratios. The set of parameters that bring the simulated ratios closest to those observed is used to define the VPR over the whole domain. The first guess of FLH is from the operational NWP model ARPEGE. Both FLH and BBT estimates can be further refined by using the cross-correlation coefficient $\rho_{\mathrm{hv}}$ (Tabary et al., 2006). This method is computationally efficient, and the overall bias induced by the bright band is most of the time well corrected. However, by defining a unique VPR, the spatial variability of the precipitation is ignored, leading to significant local biases. For instance, when a cold front crosses the radar domain, differences in brightband heights exceeding $1000 \mathrm{~m}$ can be observed between the front and the rear of the precipitating area. A unique VPR, and consequently a unique freezing-level height, will necessarily generate over- and/or underestimations of the brightband altitude in some parts of the domain, leading to significant over- and/or undercorrection of the reflectivity. Also, by hypothesising a constant rain rate between the bottom of the bright band and the surface, ordinary processes such as evaporation or enhancement of the precipitation are not well captured. These limitations are partially overcome in the operational processing of the final $5 \mathrm{~min}$ QPE product by an adjustment using hourly rain gauge and radar data from the past hours (up to $40 \mathrm{~h}$ ). The adjustment factor is defined as the ratio between the total rain-gauge accumulation and the corresponding radar accumulation (with greater weight given to the most recent hourly accumulation). Only rain-gauge accumulation within $100 \mathrm{~km}$ from the radar and larger than 0.6 $\mathrm{mm}$ is used in the calculation. The QPE processing used for comparison in this study (referred to as "Panthere QPE") is identical to the operational QPE processing except for the adjustment that for the sake of simplification is calculated using the accumulation ratios from the current hour only.

\subsection{AROME-NWC and the radar forward operator}

The novelty of the method presented in this paper is to take the simulated VPRs produced by the French operational model AROME-NWC (Auger et al., 2015) as input. This new high-resolution model, especially designed for now-

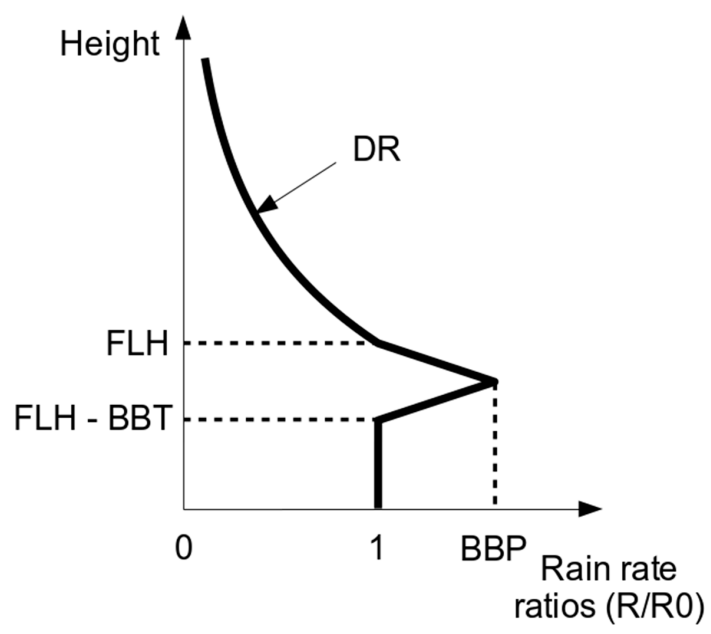

Figure 1. Idealised VPR used for the operational correction of reflectivities (Tabary, 2007) expressed in terms of rain rate ratios. FLH: freezing level height; BBP: bright-band peak; BBT: brightband thickness; DR: decreasing rate above the freezing level.

casting, is based on the AROME mesoscale model (Seity et al., 2011; Brousseau et al., 2016), which provides the lateral boundary conditions and the first-guess file. AROMENWC is run every hour and produces short-range forecast outputs up to $6 \mathrm{~h}$ on a domain covering France and adjacent areas. The vertical grid (90 levels) is stretched from 10 to around $30000 \mathrm{~m}$ above the ground and the horizontal resolution is $1.3 \mathrm{~km} \times 1.3 \mathrm{~km}$. AROME is a non-hydrostatic and convection-permitting model using a one-moment bulk microphysical scheme called ICE3, which predicts the contents of six water species: vapour, cloud water, rainwater, graupel, snow aggregates and pristine ice. The temperature and hydrometeor contents from AROME-NWC are taken as input for a polarimetric radar forward operator (Caumont et al., 2006; Augros et al., 2016) that simulates the horizontal reflectivity $Z_{\mathrm{hh}}$ (in dBZ unit) as well as the following polarimetric variables: the differential reflectivity $\left(Z_{\mathrm{dr}}\right)$, the differential propagation phase shift $\left(\phi_{\mathrm{dp}}\right)$, the specific differential phase $\left(K_{\mathrm{dp}}\right)$, the copolar correlation coefficient $\left(\rho_{\mathrm{hv}}\right)$, the specific and differential attenuations $\left(A_{\mathrm{hh}}\right.$ and $\left.A_{\mathrm{dp}}\right)$, and the backscattering differential phase $\left(\delta_{\mathrm{hv}}\right)$. The horizontal regular grid of the model $(1.3 \mathrm{~km} \times 1.3 \mathrm{~km})$ is preserved, but within the vertical columns those variables are projected onto the radar beam geometry by the forward model that, for a given elevation, takes into account the bending and broadening of the beam. Rain, graupel and snow particles are modelled as oblate spheroids, while pristine ice particles are modelled as spheres because of their random orientation. Their backscattering and forward scattering coefficients are computed following the transition matrix (T-matrix) method (Mishchenko et al., 1996). For better efficiency, the operator uses T-matrix lookup tables computed in advance for each hydrometeor type and radar wavelength (X, S and $\mathrm{C}$ bands). 
In order to only retrieve observable values of reflectivity, all the reflectivities that fall below the radar minimum detectable reflectivity $\left(Z_{\text {min_detect }}\right)$ are set to "no detection". In the current radar processing chain, $Z_{\text {min_detect }}$ is defined as the following:

$$
Z_{\text {min_detect }}(r)=Z_{\text {noise } \_100 \mathrm{~km}}+20 \log \left(\frac{r}{100}\right)+\delta,
$$

where $Z_{\text {noise_}} 100 \mathrm{~km}$ is the noise equivalent reflectivity at $100 \mathrm{~km}$ range, $r$ the distance from the radar in kilometres and $\delta$ the threshold used to reject noisy pixels. Both $Z_{\text {noise_ } 100 \mathrm{~km}}$ and $\delta$ are radar dependent. $\delta$ typically ranges between 1 and $2 \mathrm{~dB}$. With the same forward model and a similar research model (Meso-NH) at a resolution of $2.5 \mathrm{~km} \times 2.5 \mathrm{~km}$ implemented with the one-moment bulk microphysical scheme ICE3 (identical to AROME), Augros et al. (2016) have made statistical comparisons between the observed and the simulated radar variables on two Mediterranean convective events. They showed that the polarimetric forward operator produces reflectivities in overall general good agreement with observed ones. However, some discrepancies were found, especially in lower atmosphere where the simulated reflectivities tend to be underestimated, which may be due to the coarser horizontal resolution of the simulation compared to the radar observations.

\section{New radar and model combined QPE method}

To address the limitation of the current VPR correction a new methodology is proposed. This method consists of finding the simulated apparent VPR from the AROME-NWC forecast (hereafter called pseudo-observed VPR or POVPR) most resembling the observed apparent one for every radar pixel, and then to retrieve the corresponding QPE (hereafter called POVPR QPE). For an easy following of the different steps of the method described in this section, the reader can refer to the Fig. 3.

\subsection{VPR estimation}

The VPR estimation is applied separately for each $1 \mathrm{~km} \times 1 \mathrm{~km}$ pixel $p_{i}$ of the radar domain. The method developed in this study to retrieve VPRs is based on the Bayesian approach used by Kummerow et al. $(1996,2001)$ in the Goddard profiling algorithm (GPROF). This was also used by Caumont et al. (2010), Augros et al. (2018) and Borderies et al. $(2018,2019)$ for the validation and assimilation of radar reflectivity and dual-polarisation observations in the French high-resolution model AROME. In the same way, we use here a large database made of simulated profiles $\mathrm{VPR}_{\bmod }$ in the vicinity of the considered radar pixel $p_{i}$ to find the most probable VPR $\left(\operatorname{POVPR}\left(p_{i}\right)\right)$ given the observed apparent $\operatorname{VPR}_{\text {rad }}$. Thus, $\operatorname{POVPR}\left(p_{i}\right)$ is defined as a linear combination of the $\mathrm{VPR}_{\text {mod }}$ weighted by a factor $P$ depending on the distance $d$ in terms of reflectivity between the apparent simulated VPRs (VPR $\left.\mathrm{Vmod}_{\text {app }}\right)$, i.e. the projection of $\mathrm{VPR}_{\bmod }$ on the available radar elevations, and $\mathrm{VPR}_{\mathrm{rad}}$ :

$\operatorname{POVPR}\left(p_{i}\right)=\frac{1}{\sum_{j} P(j)} \sum_{j} P(j) \operatorname{VPR}_{\bmod }(j)$,

where

$$
\begin{aligned}
P(j)=\exp \left(-\frac{1}{2} \mathrm{~d}\right. & {\left.\left[\operatorname{VPR}_{\text {mod,app }}(j)\right]\right), } \\
\mathrm{d}\left[\operatorname{VPPR}_{\text {mod,app }}(j)\right]= & \frac{1}{n_{\text {elev }}} \sum_{n_{\text {elev }}} \\
& {\left[\frac{Z_{\text {hh_mod,elev }}(j)-Z_{\text {hh_rad,elev }}}{\sigma\left(h_{\text {elev }}\right)}\right]^{2}, }
\end{aligned}
$$

and

$$
\frac{1}{\sigma\left(h_{\mathrm{elev}}\right)^{2}}=\left[\frac{2}{\frac{h_{\mathrm{elev}}}{\mathrm{Alt}_{\max }}+1}-1\right]^{2} \text {. }
$$

$j$ is the index of the profiles $\mathrm{VPR}_{\text {mod }}$ in the vicinity of the profile $\mathrm{VPR}_{\mathrm{rad}}, n_{\mathrm{elev}}$ is the number of elevations where the reflectivity is valid, $Z_{\mathrm{hh} \_ \text {mod,elev }}$ and $Z_{\mathrm{hh} \_ \text {rad,elev }}$ are the simulated and observed reflectivities respectively, and $\sigma\left(h_{\mathrm{elev}}\right)$ is a weighting function depending on the height of the elevation $h_{\text {elev }}$ normalised by the maximum altitude of the radar dataAlt $_{\max }$ (set to $12000 \mathrm{~m}$ a.s.l. in this study). This formulation of $\sigma$ permits us to give more weight to the lowest elevations. $P$ is equal to 1 for a perfect simulated apparent VPR $\left(\mathrm{VPR}_{\text {mod, app }}=\mathrm{VPR}_{\mathrm{rad}}\right)$ and tends towards 0 as the difference between VPRs increases.

This procedure is repeated for each pixel $p_{i}$ of the area covered by the radar. Some settings are imposed to, on the one hand, limit the time computing and, on the other hand, to help the algorithm find the most appropriate VPR. First and foremost, simulated reflectivities below $Z_{\text {min_detect }}(p i)$ (see Eq. 1) are considered as non-precipitating. Then, the distance for exploring the simulated VPRs around $p_{i}$ is set to a maximum of $100 \mathrm{~km}$ as proposed by Augros et al. (2018). At the full resolution of AROME-NWC $(1.3 \mathrm{~km})$, it represents more than 18000 simulated VPRs to analyse. We chose to keep the spatial extent of the data set to take into account spaceshifting of the simulated precipitation with respect to the observations. Thus, to reduce the data set and consequently the computing time, only one point out of four of the simulation in each horizontal direction has been used, dropping the number of VPRs to analyse to about 1200. Moreover, for every observed and simulated vertical profile of reflectivity that contains a non-precipitating layer surrounded by precipitating layers, only the lower precipitating part is kept. By doing so, we make the hypothesis that the lower precipitating layer is unrelated to the upper one. We also forced the selected VPRs to be in the same air mass as that in $p_{i}$ through a condition on the freezing level. The $0{ }^{\circ} \mathrm{C}$ isotherm at $p_{i}$ location is estimated by one of the co-located points of the AROME 


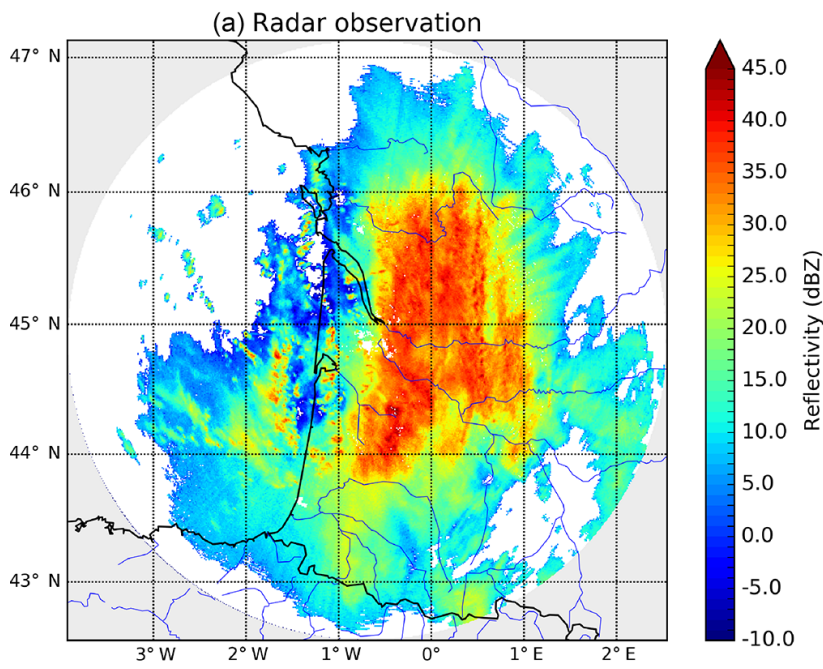

(b) AROME-NWC simulation

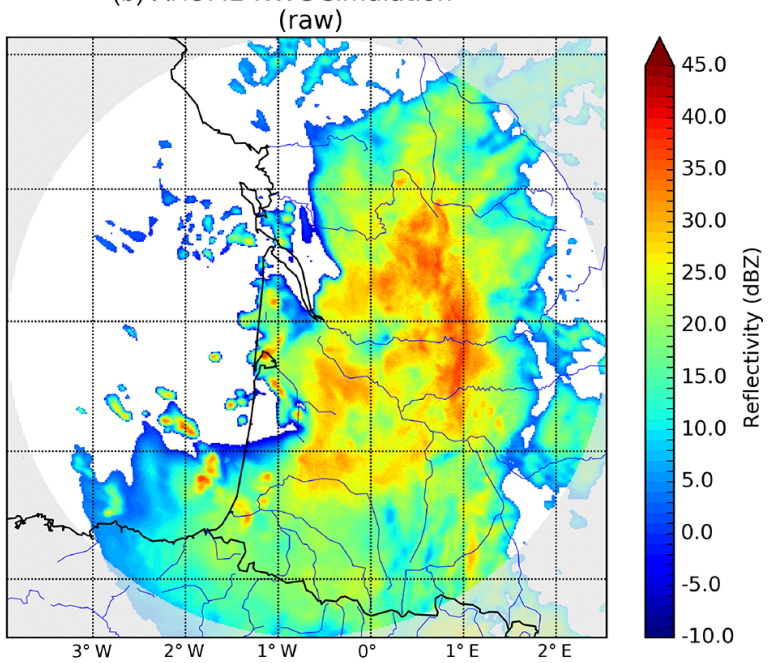

(c) AROME-NWC simulation (with QM)

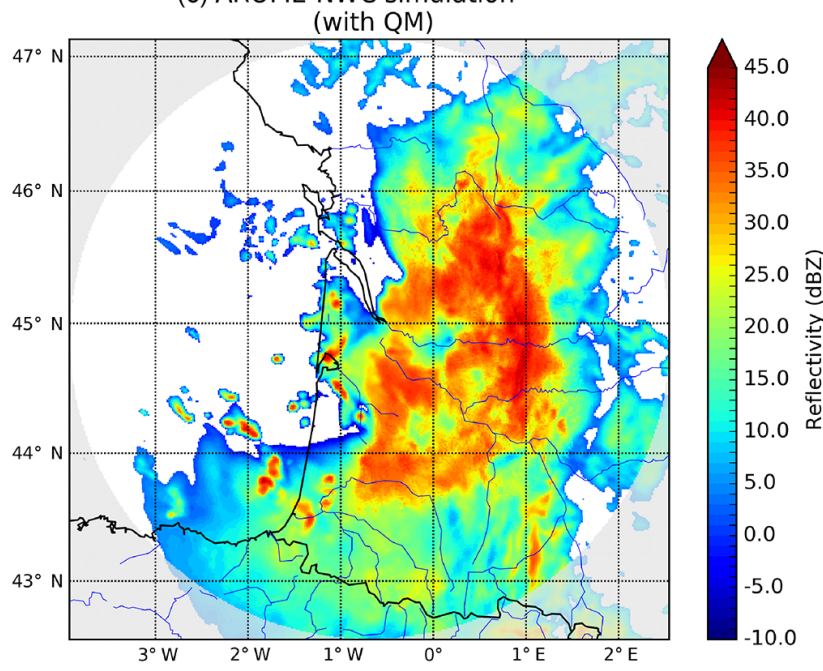

(d) QM correction

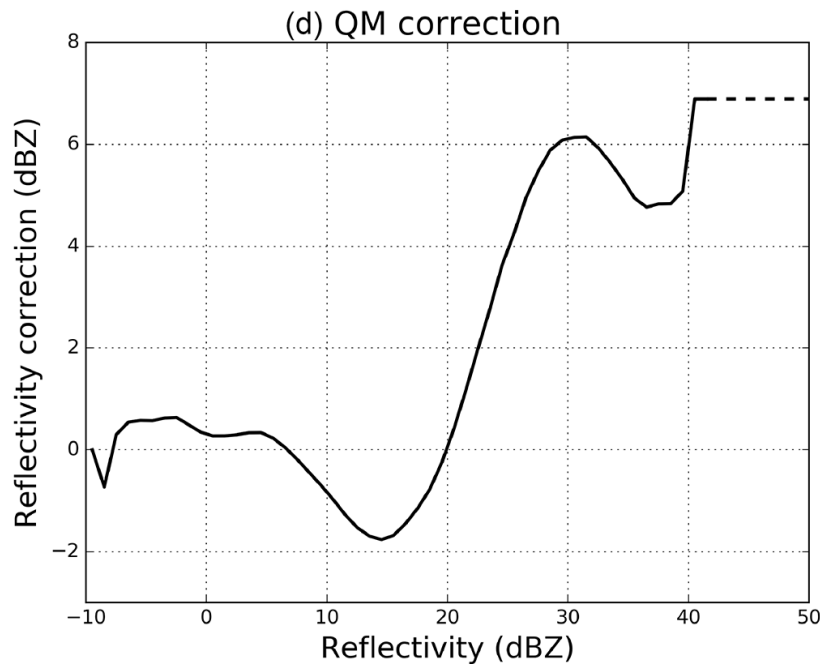

Figure 2. (a) Observed radar reflectivity from the radar of Bordeaux at the elevation $0.4^{\circ}$ on 3 March 2017 at 23:00 UTC. (b) Corresponding raw simulated radar reflectivity from AROME-NWC (run of 21:00 UTC). (c) Same as (b) but corrected by quantile mapping. (d) Reflectivity correction $\mathrm{Cz}$ resulting from the quantile mapping. The extension of the correction for higher reflectivities is represented by dashed lines.

analysis. Model displacement errors could introduce errors in the determination of the correct $0{ }^{\circ} \mathrm{C}$ isotherm, but the AROME analysis is performed every hour and can represent the freezing with a smaller error than the one induced by the use of a unique value for the entire domain in the current operational method. VPRs that have a freezing level height $300 \mathrm{~m}$ higher or lower than that in $p_{i}$ are excluded from the data set. Additionally, simulated VPRs where the ground level is higher by more than $300 \mathrm{~m}$ above the ground level of $p_{i}$ are also eliminated from the data set. Indeed, VPRs from higher terrain are, by nature, not defined at the ground altitude of $p_{i}$ and consequently cannot provide relevant information about the vertical structure of the precipitation at this altitude. On the contrary, keeping VPRs from lower terrain allows us to potentially extend the simulated VPR data set for mountainous pixels. Finally, in order to give more importance to the nearby VPRs, only the 100 closest remaining VPRs are kept. In the hypothesis in which no VPR would be excluded from the initial data set (1200 VPRs) during the previous filtering steps described above, this last step would keep VPRs of a distance of less than $30 \mathrm{~km}$ away from $p_{i}$.

Reducing the number of candidates helped to run the algorithm in a reasonable time for research (about $12 \mathrm{~h}$ for a $1 \mathrm{~h}$ accumulation over the entire radar domain). The performance of our algorithm could be highly improved by parallelising the processing (for the moment each radar pixel is processed separately) to meet operational requirements. The use of clustering techniques (to select the most suitable profiles) as well as the use of a three-dimensional reflectivity 


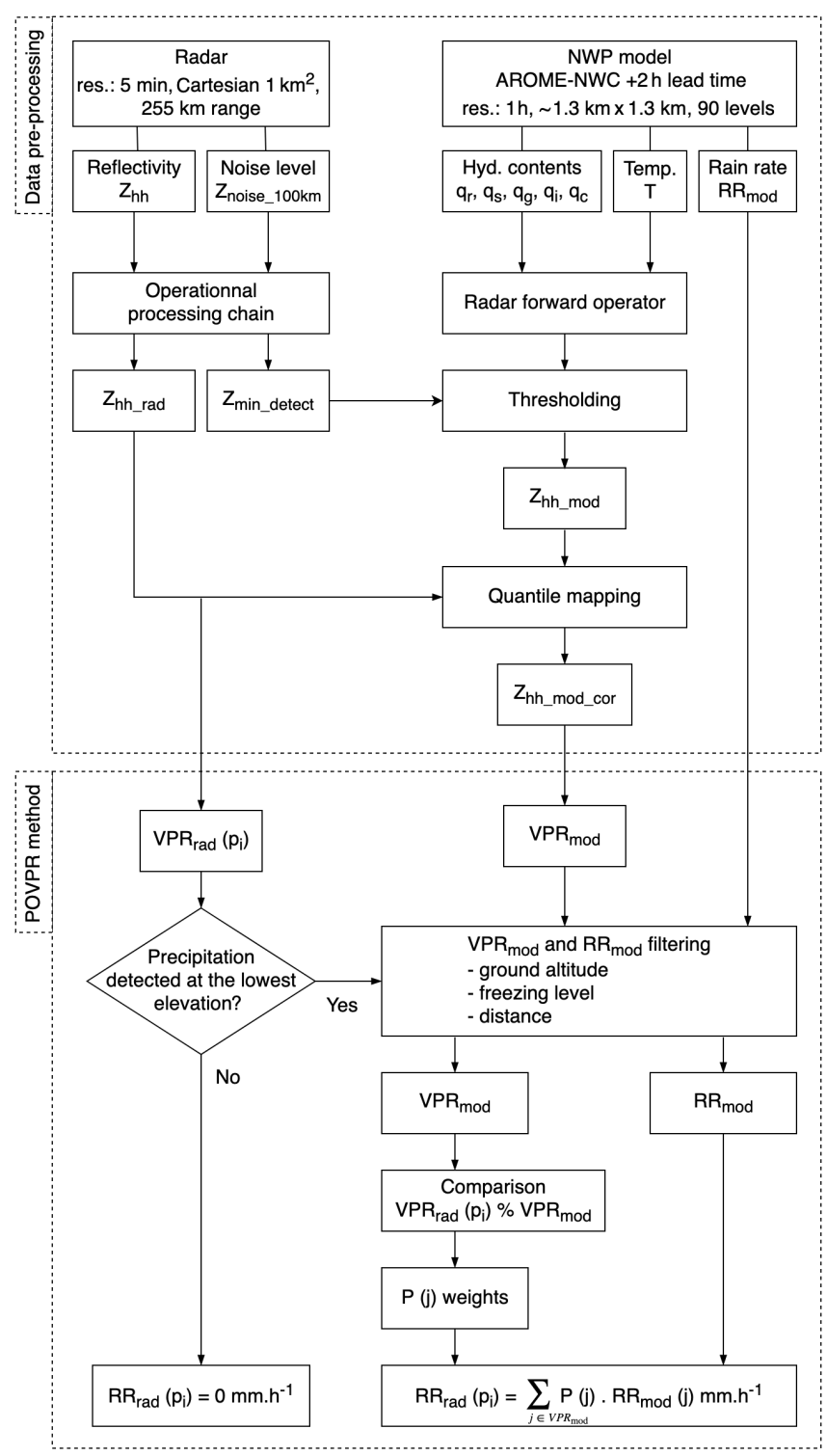

Figure 3. Process flow chart of the data pre-processing and the POVPR method for computing a pixel-wise ground rain rate from observed and simulated reflectivities.

field projected on a regular grid could also considerably improve the algorithm performance.

\subsection{Model bias correction}

To maximise the chances of finding the simulated apparent VPRs that best fit the observations, a model bias correction is used to bring a maximum number of simulated observations as close as possible to the observed ones. Simulated observations can be biased either because the model itself is biased (approximation in the model physics, representativeness errors) or because the radar forward operator is biased or both. For simplicity, all the model biases are corrected by applying a quantile mapping correction $(\mathrm{QM})$, a method commonly used in climatic simulations (Lafon et al., 2013). Thus, this correction is applied every hour and is used to match the distributions $\left(D_{\mathrm{mod}}\right)$ of the simulated reflectivities produced by the model $\left(Z_{\mathrm{hh} \_ \text {mod }}\right)$ with the observed distributions $\left(D_{\mathrm{rad}}\right)$ computed by aggregating all $5 \mathrm{~min}$ radar reflectivity scans during the hour centred around the model time. Ideally, the quantile mapping correction should be made not only according to the reflectivity but also according to the temperature for taking into account the different phases of hydrometeors and their different response in terms of reflectivity, as well as the distance for considering the beam broadening. The chosen $1 \mathrm{~h}$ time window ensures that the range of values of each 5 min observed reflectivity data set processed by the POVPR algorithm is covered by the closest in time simulated reflectivity data set used for the VPR estimation. Some tests (not presented here) have shown that a longer temporal window gives poorer final QPE results.

To take into account the positioning errors of the simulated precipitating columns compared to the observations, a first step consists of the adjustment of the distances of these columns from the radar also by quantile mapping before the projection on the radar beam geometry. Indeed, let us suppose the observation is made of a unique precipitating column $C_{\mathrm{o}}$, which is perfectly represented by the simulated column $C_{\mathrm{s}}\left(C_{\mathrm{o}}=C_{\mathrm{s}}\right)$ but further from the radar. Due to the different beam altitudes and widths at the column locations, the projection of $C_{\mathrm{s}}$ on the radar beam geometry will be most probably different from the projection of $C_{\mathrm{o}}$ even though the unprojected columns are identical. This statement can be generalised to larger data sets. Thus, the preliminary quantile mapping correction on distances ensures that the proportions of precipitating columns at a particular distance from the radar are the same in $D_{\text {rad }}$ and $D_{\text {mod }}$ data set, which mitigates the effects of the model positioning errors. Furthermore, to have comparable samples, simulated reflectivities below the theoretical noise level are eliminated, and each elevation of the model data set is repeated as often as it is present in the radar data set. Finally, the transfer function $T_{\mathrm{Mod} \rightarrow \operatorname{Rad}}$ from $D_{\text {mod }}$ to $D_{\text {rad }}$ is evaluated and applied to simulated reflectivities to produce the corrected reflectivity ( $\left.Z_{\mathrm{hh} \_ \text {mod_cor }}\right)$ data set:

$Z_{\text {hh_mod_cor }}=T_{\text {Mod } \rightarrow \text { Rad }}\left(Z_{\text {hh_mod }}\right)$.

In a different way, we can express $Z_{\mathrm{hh} \_ \text {mod_cor }}$ as the sum of $Z_{\mathrm{hh} \_ \text {mod }}$ and a corresponding reflectivity correction $\left(C_{z}\right)$ :

$Z_{\mathrm{hh} \_ \text {mod_cor }}=Z_{\mathrm{hh} \_ \text {mod }}+C_{z}\left(Z_{\mathrm{hh} \_ \text {mod }}\right)$,

where

$C_{z}\left(Z_{\mathrm{hh} \_ \text {mod }}\right)=T_{\mathrm{Mod} \rightarrow \operatorname{Rad}}\left(Z_{\mathrm{hh} \_ \text {mod }}\right)-Z_{\mathrm{hh} \_ \text {mod }}$.

Note that the projection of simulated reflectivities is adapted to each radar pixel geometry during the VPR estimation (see next part). As a consequence, simulated reflectivities used for 
(a) Abbeville

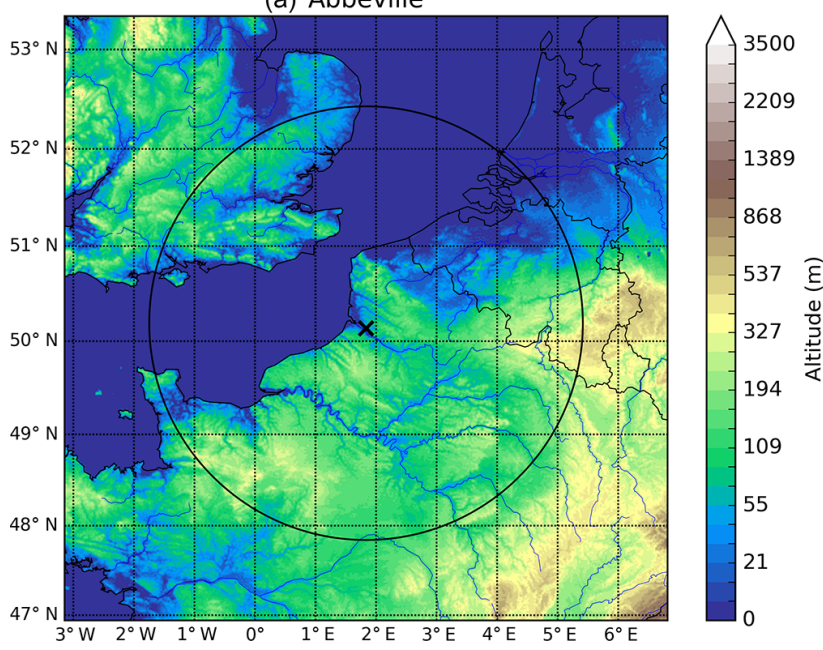

(b) Bordeaux

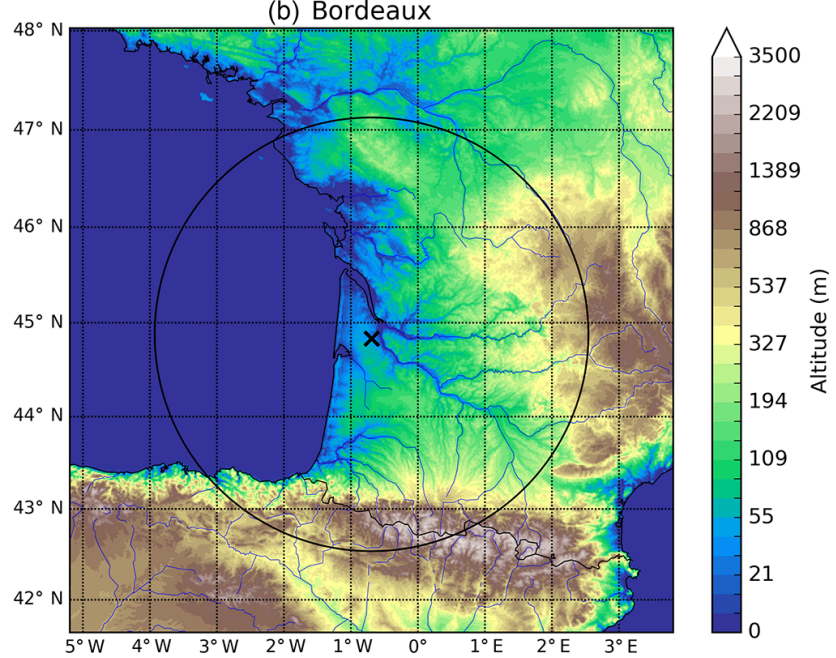

Figure 4. Topography in the Abbeville (a) and Bordeaux (b) radar areas. The radar positions are indicated by the black crosses and their $255 \mathrm{~km}$ ranges by the black circles. The domain displayed is extended by $100 \mathrm{~km}$ to represent the NWP model domain used for the computation of the POVPR accumulations.

the VPR search can outreach the ones used for the building of $T_{\text {Mod } \rightarrow \text { Rad }}$. That is why, for reflectivities exceeding the maximum reflectivity of the simulation data set $\left(Z_{\mathrm{hh} \_ \text {modmax }}\right), C_{z}$ is set to the correction value of $Z_{\mathrm{hh} \_ \text {modmax }}$ :

$C_{z}\left(Z_{\mathrm{hh} \_ \text {mod }}>Z_{\mathrm{hh} \_ \text {modmax }}\right)=C_{z}\left(Z_{\mathrm{hh} \_ \text {modmax }}\right)$.

An example of the application of the quantile mapping correction is provided in Fig. 2.

For the purpose of this study, the $2 \mathrm{~h}$ lead time forecasts from AROME-NWC are used. On the one hand, this short forecast range offers the advantages to be beyond the spinup period of the model. On the other hand, it is close enough to the analysis time so that the initial $D_{\text {mod }}$ data set can be brought as close as possible to the $D_{\text {rad }}$ data set by quantile mapping, and most representative VPR profiles can be found in the VPR estimation process. However, in situations where the simulations are too different from the observations, in terms of timing (convection initiation time not well predicted for example) or intensity (embedded convection within stratiform precipitation observed but not simulated by the NWP model for instance), the use of an adaptive time window and/or multiple model runs, could be considered.

\subsection{QPE calculation}

Once the closest simulated VPRs and their corresponding weights $P$ are found for the pixel $p_{i}$, the rain rate at the pixel $p_{i}\left(\operatorname{RR}_{\mathrm{rad}}\left(p_{i}\right)\right)$ is estimated by the $P$-weighted linear combination of the rain rates associated with each simulated VPR $\left(\operatorname{RR}_{\text {mod }}(j)\right)$ and estimated at the same altitude as the ground altitude of $p_{i}$ :

$\operatorname{RR}_{\mathrm{rad}}\left(p_{i}\right)=\frac{1}{\sum_{j} P(j)} \sum_{j} P(j) \mathrm{RR}_{\text {mod }}(j)$.
The entire procedure for generating $\mathrm{RR}_{\mathrm{rad}}\left(p_{i}\right)$ from radar and NWP model reflectivities is summarised in Fig. 3. The 5 min precipitation accumulation ACC $\left(p_{i}\right)$ is simply deduced by integrating $\mathrm{RR}_{\mathrm{rad}}\left(p_{i}\right)$ over time by assuming that the rain rate is constant during this period:

$\operatorname{ACC}\left(p_{i}\right)=\mathrm{RR}_{\mathrm{rad}}\left(p_{i}\right) 5 \mathrm{~min}$.

Operationally, a spatio-temporal interpolation of the $5 \mathrm{~min}$ rain rates is made at a $1 \mathrm{~min}$ time step to take the displacement of precipitation into account. For simplification, this has not be done here. But the stratiform nature of precipitation of the cases studied further (see Sect. 4) ensures that the error made by doing so is negligible.

Finally, similarly to the Panthere QPE calculation, we apply a simplified adjustment factor on the final radar QPEs (see Sect. 2.1). In a timely manner, it simultaneously reduces the impact of bias from radar measurements and simulated rain rates.

To deal with the possible poor performance of the NWP model, we could use the current operational algorithm as a fallback solution. For each observed radar apparent VPR, the simulated profiles are linearly combined according to the cost function described in Eqs. (3) and (4). In a situation with a low level of similarity between observed and simulated profiles, the $P$ weights used for the linear combination are rather low. As a solution, we could introduce an additional term depending on the rain rate produced by the current operational algorithm (Panthere) in the linear combination of the simulated rain rates (Eq. 10). The features of this new term would be negligible when many resembling simulated profiles are found and become predominant when the $P$ weights fall down. More simply, we could use the Panthere QPE when the sum of $P$ weights falls below a threshold to be defined. 
(a) Radar observation

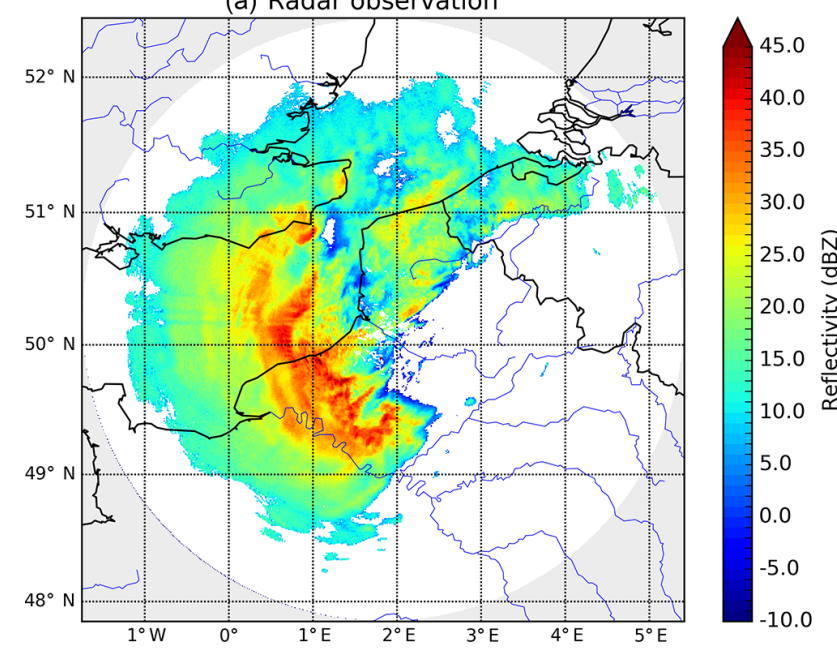

(b) AROME-NWC simulation

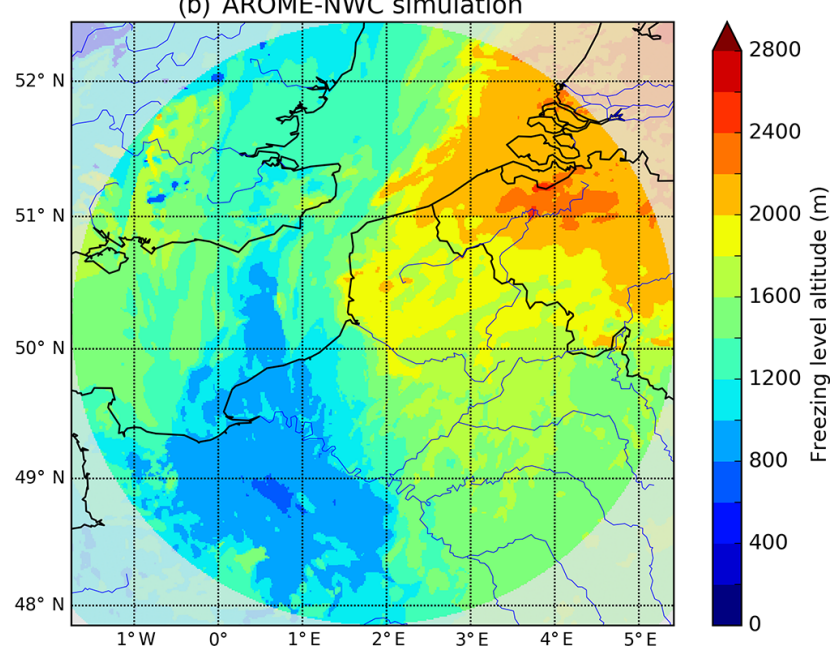

Figure 5. Observed reflectivity from the radar of Abbeville at the elevation $0.4^{\circ}$ (a) and simulated freezing level altitude from the model AROME-NWC (+2 h lead time) (b) on 30 April 2018 at 06:00 UTC.

With such a fallback procedure, in case of a poor simulation, the retrieved accumulation would be at least relatively close to the current operational one.

\section{Results}

Two stratiform case studies (30 April 2018 and 3 March 2017) affecting plain areas (see Fig. 4) were chosen to demonstrate the potential benefits of the method. In these particular situations, the variability of temperature and the precipitation fields was large and the NWP model was able to produce simulations in relatively good agreement with the observations in terms of timing, localisation and intensity. The evaluation of the new QPE method with respect to the older one is first described. Then, the results are presented for both situations studied.

\subsection{Evaluation process}

To evaluate the performance of the POVPR and the operational methods, hourly and $6 \mathrm{~h}$ rain-gauge accumulations (resolution of $0.2 \mathrm{~mm}$ ) are compared with the co-located retrieved radar accumulations. For clarity, accumulations are removed from the data set if (i) the rain gauge has a class equal to 5 according to the World Meteorological Organization (WMO) classification, (ii) the radar was not able to detect any signal (signal weaker than noise level or radar beam above the precipitation) or (iii) the simulated freezing level height above the ground level is lower than $300 \mathrm{~m}$ (enhanced risk of snow which cannot be correctly measured by the nonheated rain gauges from the operational network). Once the hourly and $6 \mathrm{~h}$ accumulations data set are built, the root mean square error (RMSE), the mean bias and the Pearson correlation coefficient $(r)$ are computed for both radar data sets
(Panthere and POVPR) by considering the rain-gauge data set as a reference. We also compute the differences between the mean hourly RMSEs from the POVPR QPEs and the mean hourly RMSEs from the Panthere QPEs according to the distance from the radar.

\subsection{Back-bent occlusion of the 30 April 2018}

On 30 April a quasi-stationary low concerned northern France. Its warm and cold fronts affected most part of the country, and its warm sector occluded on the northernmost areas. The latter wrapped around the low, forming a socalled back-bent occlusion, which brought cold temperatures and continuous precipitation, especially in Normandy where some snow was locally witnessed. As an illustration of these features, Fig. 5 displays the observed reflectivity and the freezing level field predicted by AROME-NWC (04:00 UTC run) at 06:00 UTC. The heaviest rainfalls occurred between 03:00 and 09:00 UTC with accumulations up to $25 \mathrm{~mm}$ measured by the rain gauges.

During this event, the correctness of the accumulations computed operationally (Panthere) compared to those measured by the rain gauges was really poor (see Fig. 6a), with a strong overestimation in a corridor at a distance between roughly 45 and $85 \mathrm{~km}$ from the radar and a significant underestimation beyond. A deeper analysis of the lower radar scans (not shown here) reveals all the typical features of a bright band in the area of overestimation: enhanced reflectivity, differential reflectivity $\left(Z_{\mathrm{dr}}\right)$ and specific differential phase $\left(K_{\mathrm{dp}}\right)$, as well as a low cross-correlation coefficient $\left(\rho_{\mathrm{hv}}\right)$. At 06:00 UTC, from the lower radar scan $\left(0.4^{\circ}\right.$ elevation), the bright-band top can be estimated to be at an altitude of approximately $1000 \mathrm{~m}$ a.s.l. at that location. This is consistent with the freezing level altitude predicted by AROMENWC (see Fig. 5). However, the operational evaluation of the 
(a) Panthere

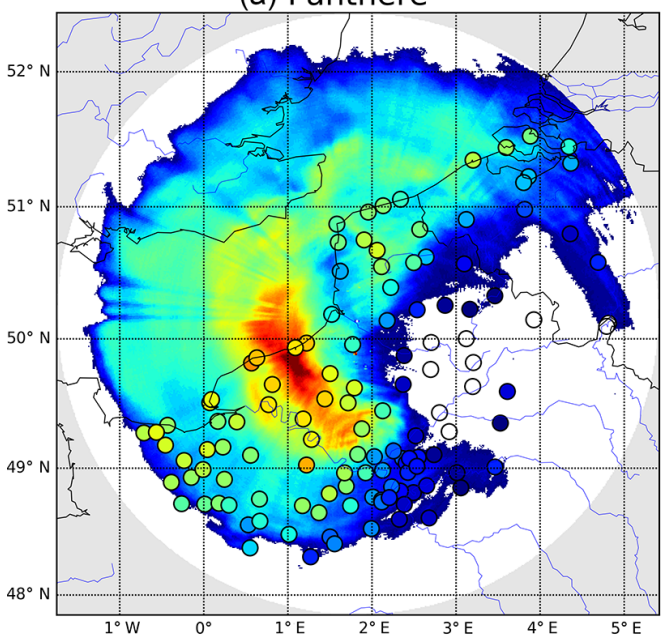

(c) POVPR - Panthere

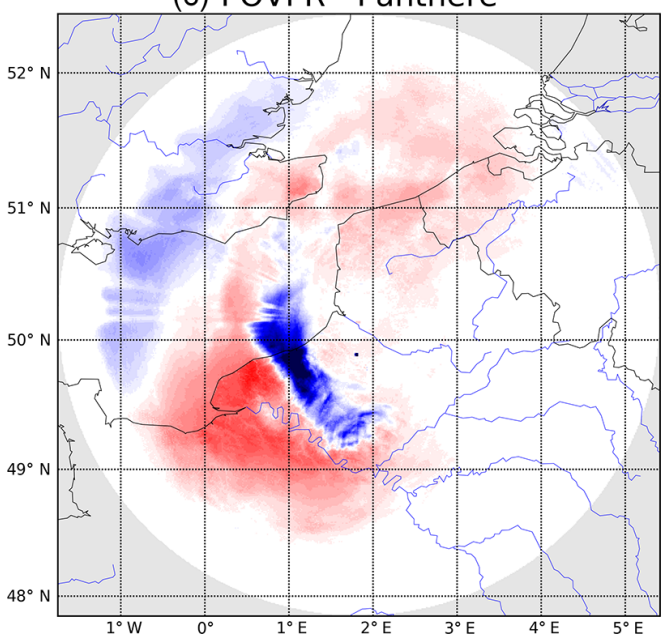

(b) POVPR

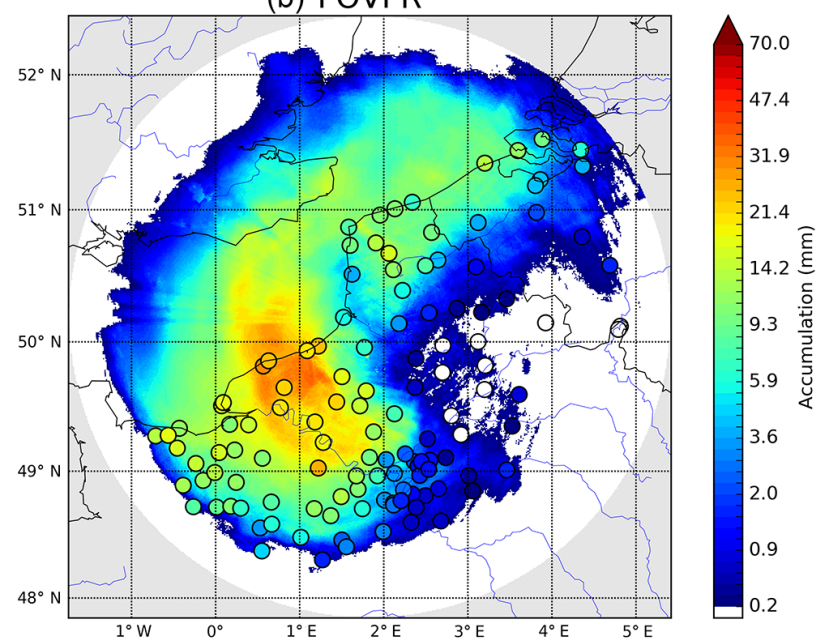

(d) POVPR vs. Panthere

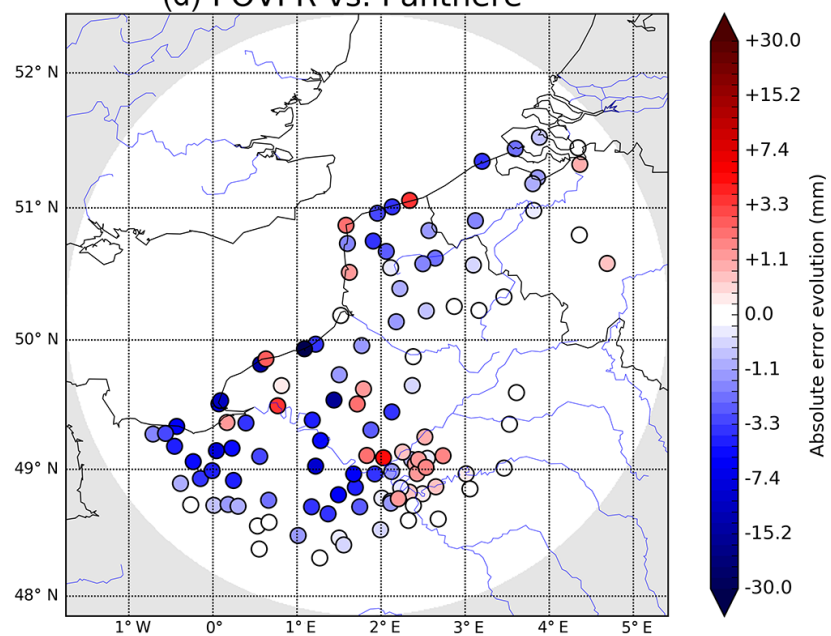

Figure 6. The $6 \mathrm{~h}$ accumulations for the 30 April 2018 event between 03:00 and 09:00 UTC on the Abbeville radar domain (255 km range) with the operational method Panthere (a) and the POVPR method (b). Rain-gauge accumulations where any precipitation has been detected by the radar are represented by circles. (c) Difference between both spatial accumulations (POVPR - Panthere). (d) Absolute error evolution between both methods at the rain-gauge locations.

bright-band top altitude made from the $\rho_{\mathrm{hv}}$ radar fields prior to the determination of the VPR (see Sect. 3.1) led to a freezing level altitude of $2000 \mathrm{~m}$ a.s.l. Further investigations show that this overestimation is in particular due to the high spatial variability of the freezing level height combined with the radar beam geometry. The bright band in the western cold air mass is too low to be sampled by most of the radar beams. Consequently, the bright-band top altitude retrieved by the radar scans is more representative of the warm air mass close to the radar location than the cold air mass further west where the QPE values are very biased.

The overestimation of the freezing level altitude has different impacts on the VPR correction (see Fig. 1) depending on the distance from the radar. Close to the radar, where the beam intercepts the bright band, reflectivities are considered to be in the rain and therefore are not corrected. It finally in- duces a strong overestimation of the ground rainfall accumulations. Further from the radar, where the beam is above the freezing level, three configurations lead to an underestimation of the precipitation at the ground level: (i) reflectivities are still considered to be in the rain part and are not enhanced as they should be, (ii) reflectivities are incorrectly flagged as lying in the bright band and are consequently wrongly reduced by the VPR correction or (iii) reflectivities are rightly considered as snowy but are insufficiently corrected because of the underestimation of the thickness between the radar beam and the freezing level altitudes.

The POVPR method is much more reliable in this situation (see Fig. 6b-d) thanks in particular to the constraint imposed on the freezing level altitude during the research of the most appropriate simulated VPR (see Sect. 3.1). The estimations, which are biased due to the overestimation of the 
(a) Panthere vs. rain gauges

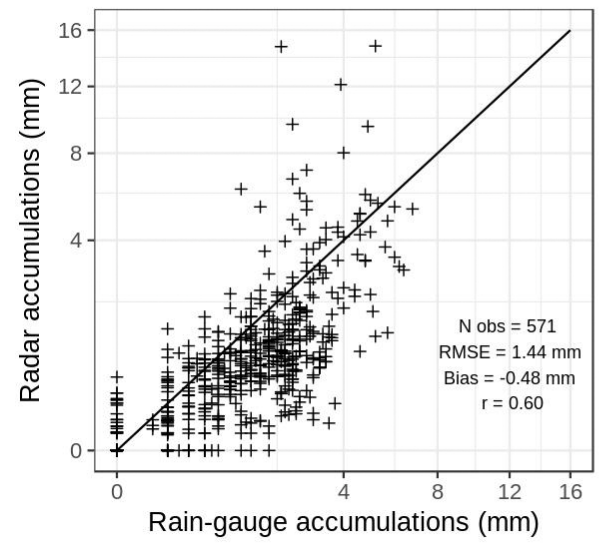

(c) Panthere vs. rain gauges

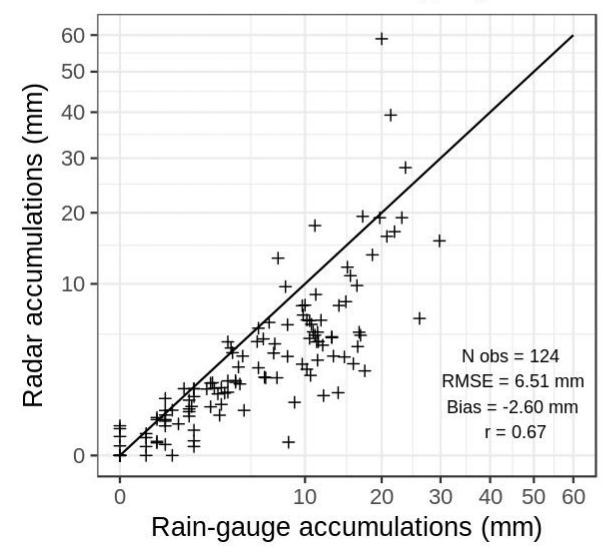

(b) POVPR vs. rain gauges

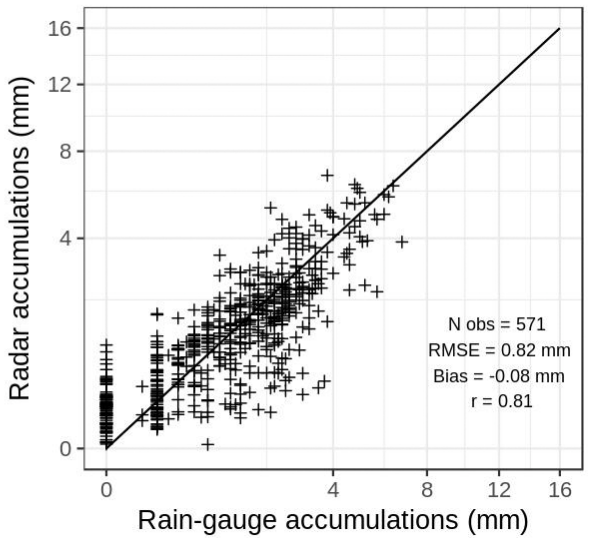

(d) POVPR vs. rain gauges

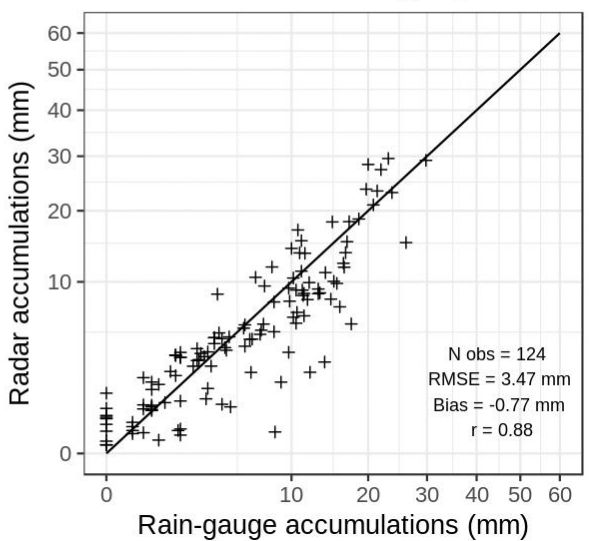

Figure 7. Comparisons between rain-gauge and radar accumulations computed for the 30 April 2018 event between 03:00 and 09:00 UTC on the Abbeville radar domain. (a-b) Hourly accumulations; (c-d) $6 \mathrm{~h}$ accumulations; (a-c) operational method Panthere; (b-d) POVPR method. The number of observations $\left(N_{\mathrm{obs}}\right)$, the root mean square error (RMSE), the mean bias (Bias) and the Pearson correlation coefficient $(r)$ are also displayed. Data in which the lowest valid radar elevation did not detect any precipitation (no precipitation or beam too high) were removed from the data set.

freezing level altitude described above, seem to be at least partially corrected as illustrated by the difference between Panthere and POVPR accumulations (see Fig. 6c). The computed scores clearly show a significant improvement compared to the Panthere QPE. The RMSEs of the hourly and $6 \mathrm{~h}$ accumulations are reduced by $43 \%$ and $47 \%$ respectively, the mean biases are mitigated and approach zero, and the Pearson correlation coefficients grow from 0.60 and 0.67 to 0.81 and 0.88 respectively. Those improvements are illustrated by the scatter plots of these accumulations (see Fig. 7). We also notice that these performances are observed all along the radar range (see Fig. 8a) and especially at the ranges where the lower beam intercepts the bright band (45 to $85 \mathrm{~km}$ ). More generally, $65 \%$ of mean hourly RMSEs at rain-gauge locations are reduced compared to the Panthere QPE ones. But these different performances cannot be fully explained by the condition on the freezing level. Indeed, the comparison between the median simulated VPR on the radar domain relatively to the freezing level and the operational one used for the reflectivity correction shows many differences (see Fig. 9a): (i) a much more important variability of the simulated VPR underlined by the large interdecile range, (ii) a strong difference between the reflectivity at the freezing level and its value in the liquid phase which translates into the need to use a different $Z-R$ relationship for the conversion of snowy reflectivities into rain rates $(Z-S$ relationship) and (iii) a non-constant simulated reflectivity towards the ground below the bright band revealing the evaporation and/or enhancement processes of rainfall. All these statements illustrate the potential benefits of the POVPR method compared to the operational VPR correction.

\subsection{Cold front of 3 March 2017}

The second case presented in this study focuses on the cold front that passed through southwestern France on 3 and 


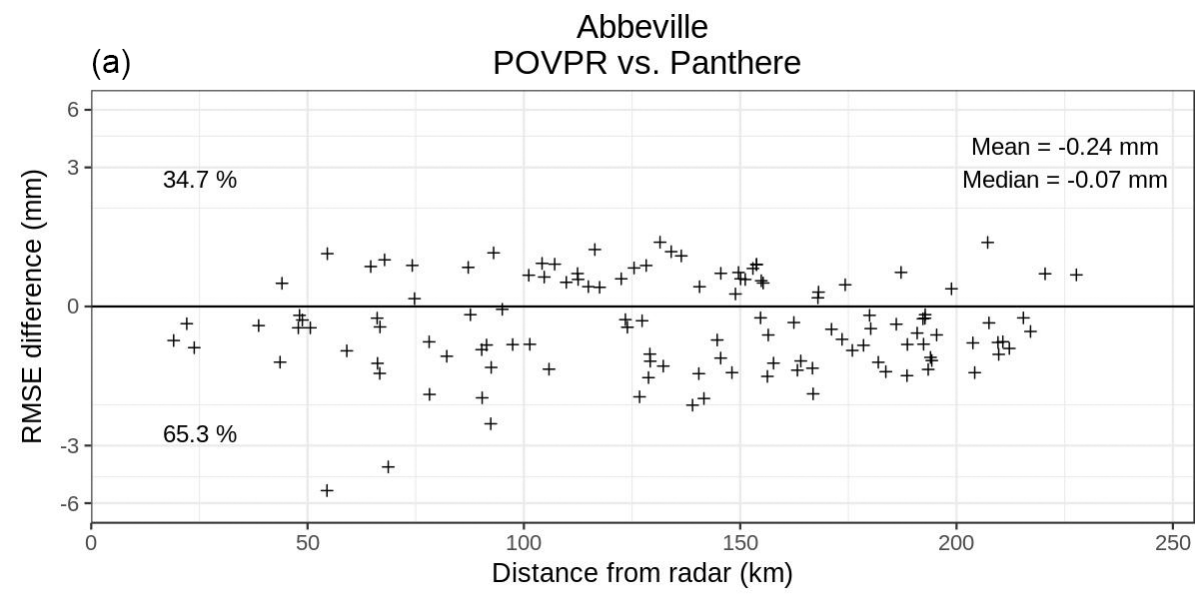

(b)

Bordeaux

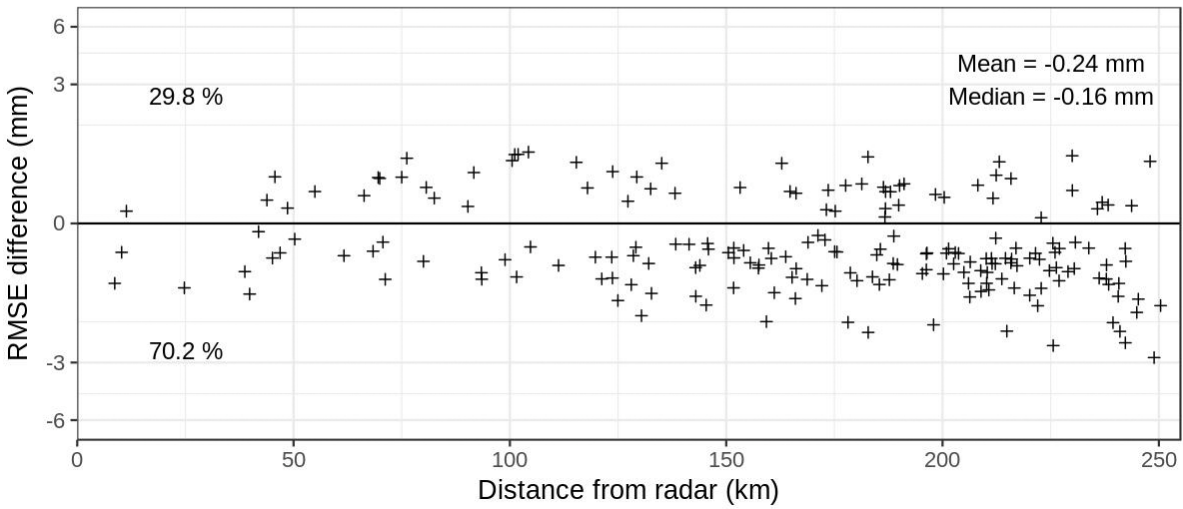

Figure 8. Differences between mean hourly RMSEs at the rain-gauge locations from the POVPR QPE and from the Panthere QPE according to the distance from the radar for the 30 April 2018 event between 03:00 and 09:00 UTC on the Abbeville radar domain (a) and for the 3 March 2017 event between 18:00 and 00:00 UTC on the Bordeaux radar domain (b). Negative values indicate a better estimation of the POVPR QPE (lower RMSE) and positive values mean the opposite. The percentages of positive and negative values of RMSE difference are also indicated.

4 March 2017. The freezing level rapidly dropped from an altitude of about $2800 \mathrm{~m}$ to roughly $1200 \mathrm{~m}$ (and even lower on the Pyrenees foothills).

The POVPR method was applied to the operational reflectivities from the C-band polarimetric radar located in Bordeaux. The western side of the radar domain is offshore and the continental terrain is mainly flat, except in the extreme south and south-east parts of the domain where the Pyrenees and the Montagne Noire reach 3400 and $1200 \mathrm{~m}$ above sea level respectively (Fig. 4b). The radar coverage is almost perfect, with few beam blockages.

Figure 10 displays a snapshot of the situation through the radar reflectivity at the lowest elevation $\left(0.4^{\circ}\right)$ and the simulated freezing level altitude from AROME-NWC, both at 21:00 UTC. The extent of the precipitating area and the relatively slow motion of the front $\left(35\right.$ to $40 \mathrm{~km} \mathrm{~h}^{-1}$ ) permitted significant accumulations (up to $40 \mathrm{~mm}$ ) over the major part of the domain. The first part of the episode (18:00 to
00:00 UTC) is of particular interest as the operational radar QPE Panthere produced notably biased estimations (see Fig. 11a) in two distinct areas: (i) over the Pyrenees foothills and the adjacent plains (extreme south of the domain) where radar rainfall estimations are much lower than the rain-gauge accumulations and (ii) over the western foothills of the Massif Central range (far eastern part of the domain) where the radar largely overestimated the precipitation amounts.

A west-to-east vertical cross section of the simulated reflectivity by AROME-NWC at 21:00 UTC (see Fig. 13a) shows that virgae (precipitation evaporating before reaching the ground) are present ahead of the main precipitation core associated with the cold front. Once you move away from the radar, the altitude of the lower beam $\left(0.4^{\circ}\right)$ increases significantly and cannot consequently sample the lower part of the atmosphere. In this case, virgae are seen by the radar similarly as precipitation reaching the ground level. Because the beam is above the freezing level at this range, the opera- 

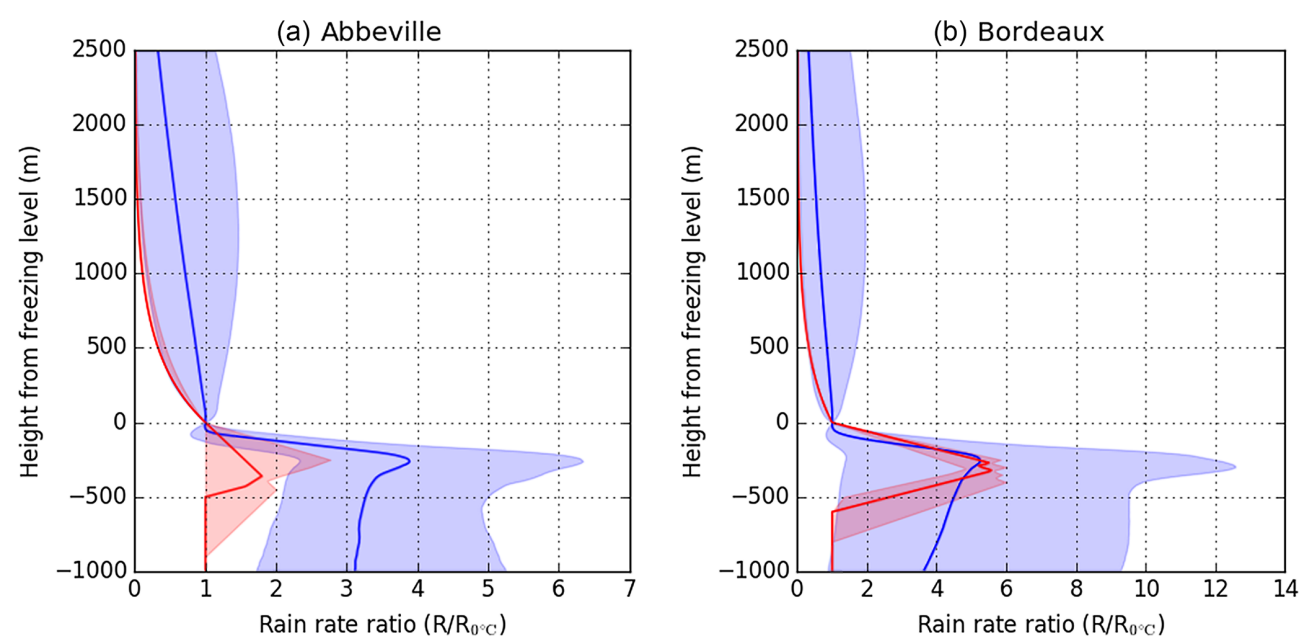

Figure 9. (a) Median VPR predicted by AROME-NWC for 30 April 2018 at 06:00 UTC on the Abbeville radar domain (blue) and median VPR of the VPRs used operationally between 05:30 and 06:30 UTC for the correction of reflectivities (red). VPRs are expressed as rain rate ratios, rain rate at the freezing level $\left(R_{0}{ }^{\circ} \mathrm{C}\right)$ being the reference. Only profiles with a rain rate greater than $0.1 \mathrm{~mm} \mathrm{~h}^{-1}$ at the freezing level have been kept. The first and last deciles are delimited by the shaded areas. (b) Same as (a) for 3 March 2018 at 23:00 UTC on the Bordeaux radar domain.

(a) Radar observation

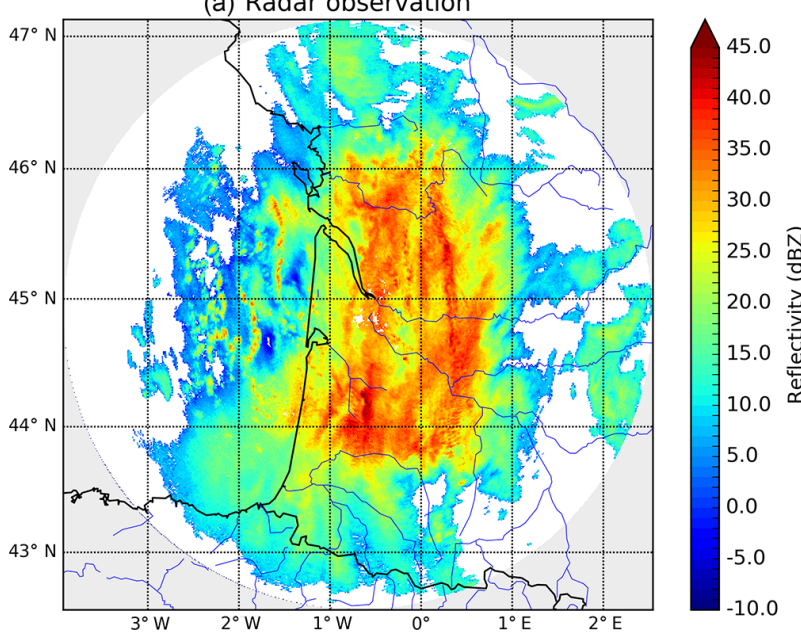

(b) AROME-NWC simulation

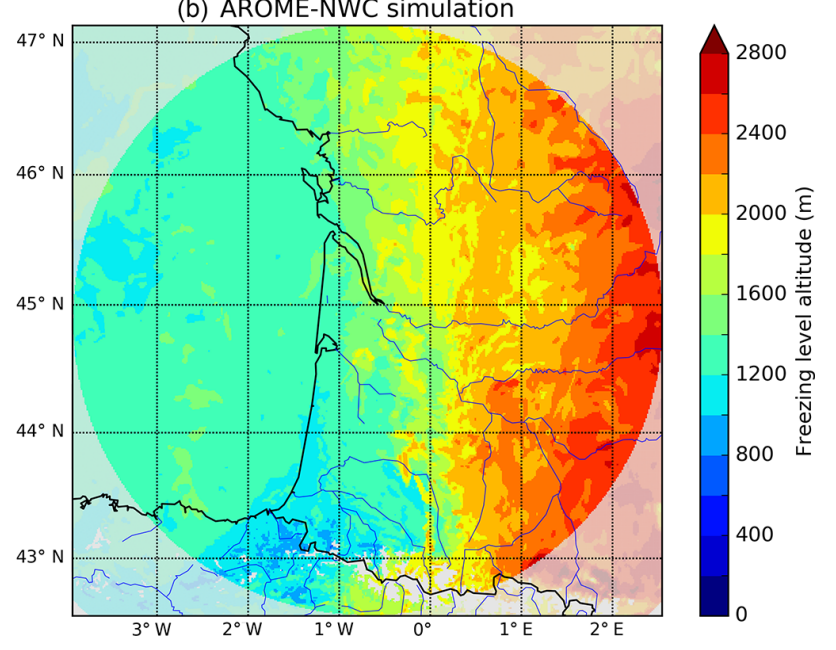

Figure 10. Same as Fig. 5 for 3 March 2017 at 21:00 UTC on the radar of Bordeaux.

tional VPR correction reinforces the overestimation. In the example displayed in Fig. 13, the extrapolation of the simulated reflectivity of the lowest elevation through the operational VPR correction would lead to a ground reflectivity of about $27 \mathrm{dBZ}$, that is to say a rain rate of $1.8 \mathrm{~mm} \mathrm{~h}^{-1}$ with the Marshall-Palmer relationship used in the operational system $\left(Z=200 R^{1.6}\right)$. By using simulated VPRs in the vicinity of each radar pixel, the POVPR method is able to take into account the evaporation of the precipitation during their falling in this area. As a result, the radar QPEs computed over the western foothills of the Massif Central range front are in much better agreement with the low accumulations measured by the rain gauges (see Fig. 11). Moreover, the new method is able to capture the enhanced precipitations over the Pyrenees foothills and adjacent plains. Note that the method has not been evaluated over the Pyrenees themselves because of the low freezing level altitude responsible for snowy precipitation and consequently leading to difficulties to evaluate rainfall amounts with non-heated rain gauges.

The improved performance of the POVPR method is confirmed by the scatter plots comparing hourly and $6 \mathrm{~h}$ accumulations with those measured by the rain gauges (Fig. 12). The RMSEs are reduced by $14 \%$ and $24 \%$ while the mean biases are divided by almost 2 . The Pearson correlation coefficients jump from 0.63 for the hourly accumulations and 0.70 for the $6 \mathrm{~h}$ accumulations to 0.73 and 0.84 respectively. The 
(a) Panthere

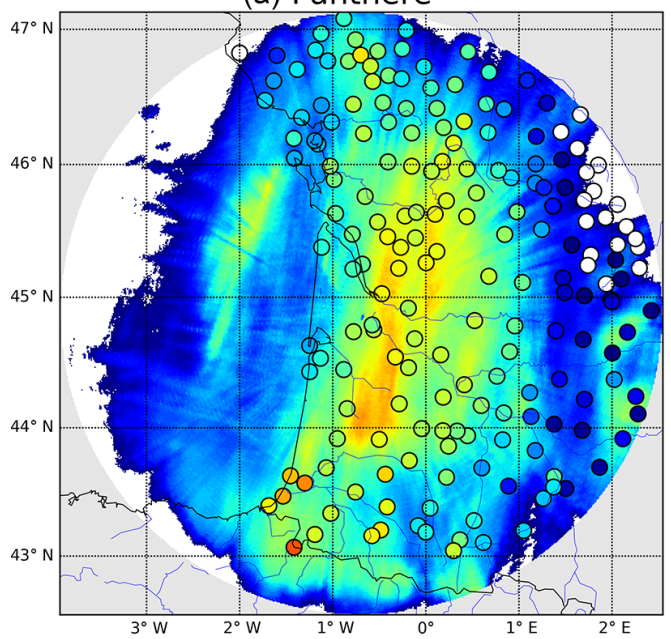

(c) POVPR - Panthere

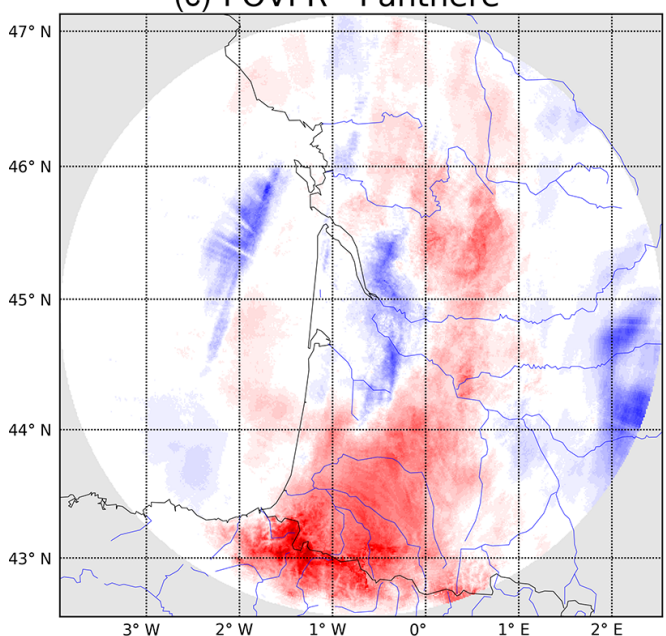

(b) POVPR

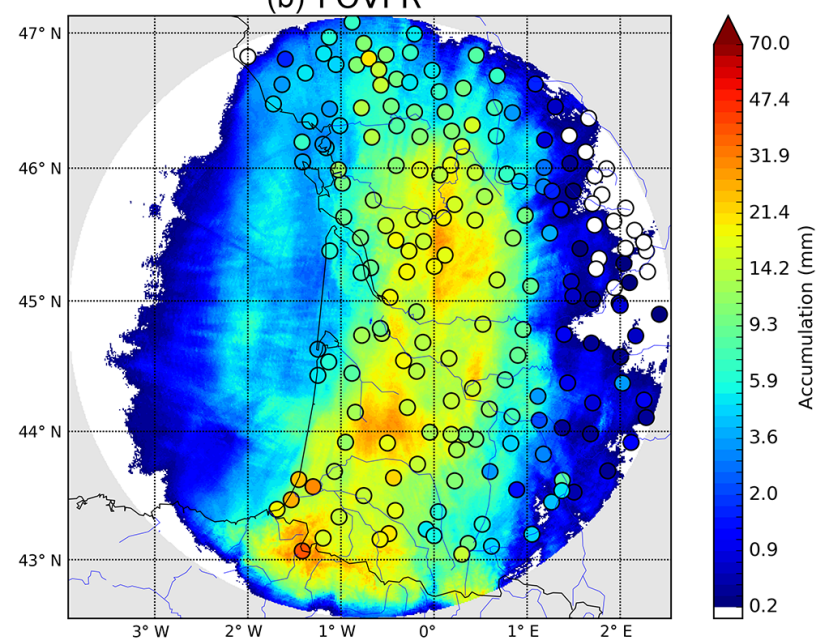

(d) POVPR vs. Panthere

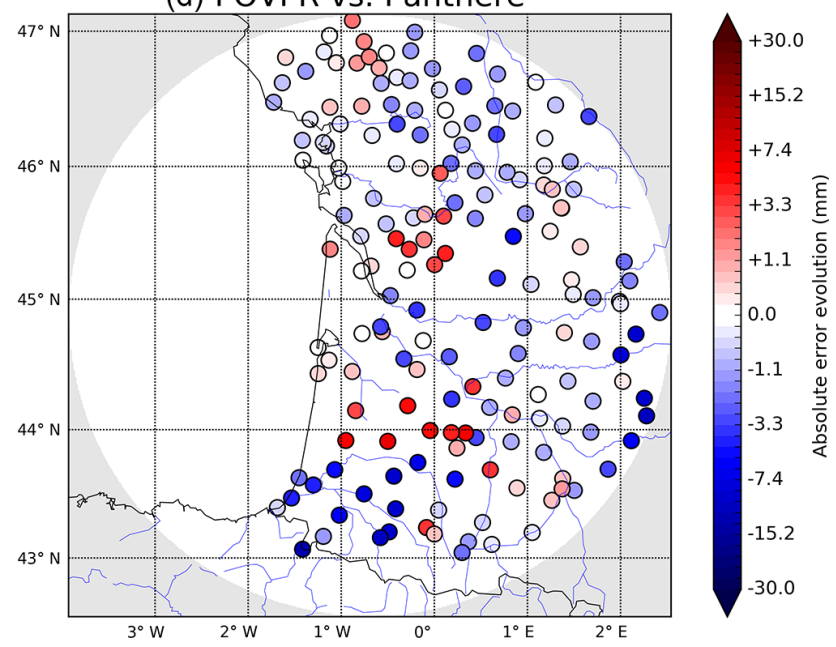

Figure 11. Same as Fig. 6 for the 3 March 2017 event between 18:00 and 00:00 UTC on the Bordeaux radar domain.

Panthere QPE overestimations observed for low rain-gauge accumulations correspond to the virga areas and are significantly mitigated with the POVPR method. The benefits of the method at greater range (beyond $100 \mathrm{~km}$ ) are clearly illustrated by the Fig. 8b. They are less evident at shorter distances. About $70 \%$ of mean hourly RMSEs at rain-gauge locations are reduced compared to the Panthere QPE ones.

Similarly to the previous case, the median simulated and operational VPRs for the POVPR QPE and the Panthere QPE at 23:00 UTC (see Fig. 9b) differ significantly in terms of shape but also intensity. The variability of the simulated VPRs emphasises the diversity of precipitation profiles over the whole radar domain, ranging from profiles with strong evaporation ahead of the cold front to very humid profiles in the main precipitating area.

\section{Conclusions}

Extrapolating rainfall at the surface from radar reflectivities measured at the beam altitude is very challenging. In operational weather services such as Météo-France, this is most commonly made thanks to a VPR correction uniformly applied over the whole radar domain. The success of this method can be explained by the fact that it is almost fully observation-based (only the simulated freezing level altitude is generally used) and it is computationally efficient, with on average good improvements in the radar QPE. However, when the spatial and vertical variabilities of the precipitation are large, selecting a unique conceptual VPR becomes very inefficient.

The purpose of this study was to illustrate the potential benefits of a new approach that takes advantage of the simulated VPRs from the NWP model AROME-NWC to perform a pixel-wise evaluation of the most probable rain rate at the 
(a) Panthere vs. rain gauges

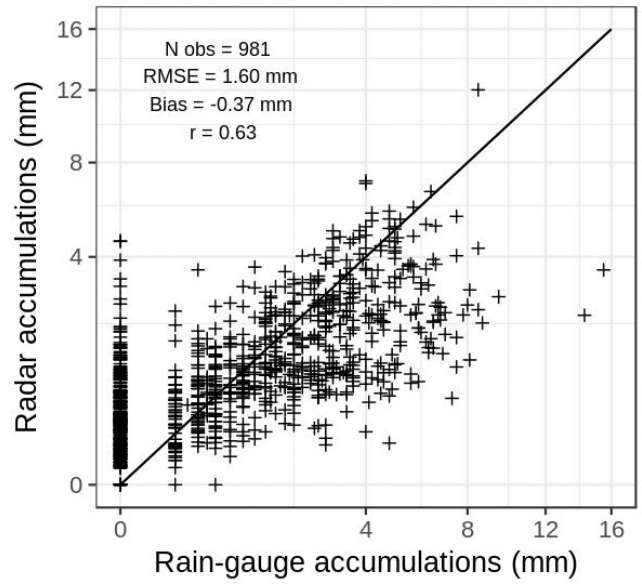

(c) Panthere vs. rain gauges

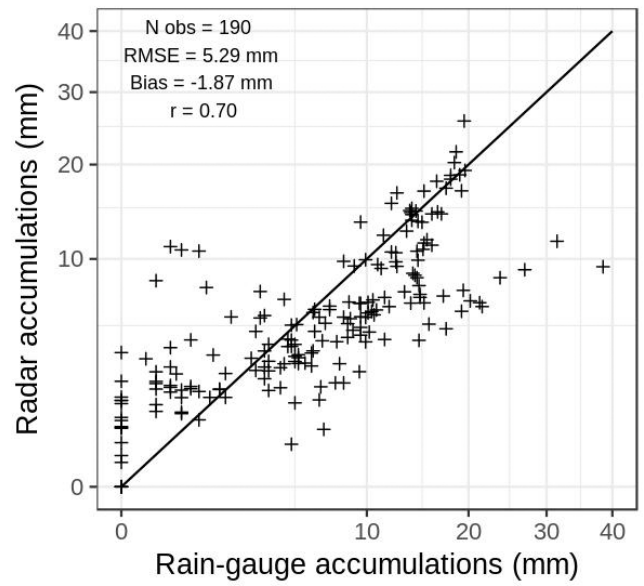

(b) POVPR vs. rain gauges

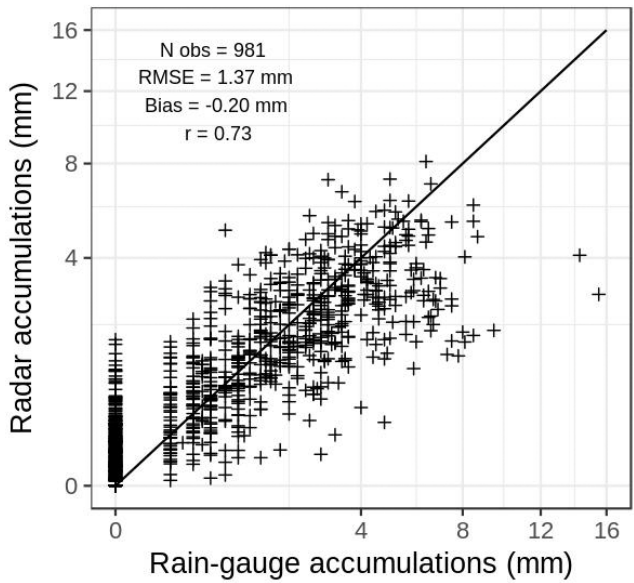

(d) POVPR vs. rain gauges

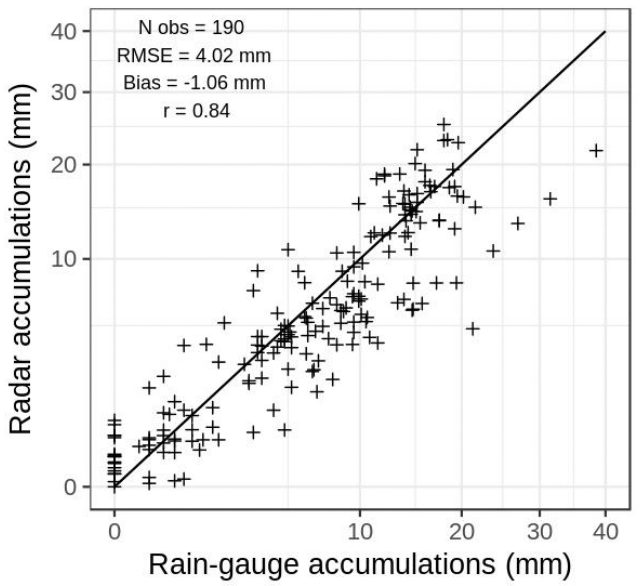

Figure 12. Same as Fig. 7 for the 3 March 2017 event between 18:00 and 00:00 UTC on the Bordeaux radar domain.
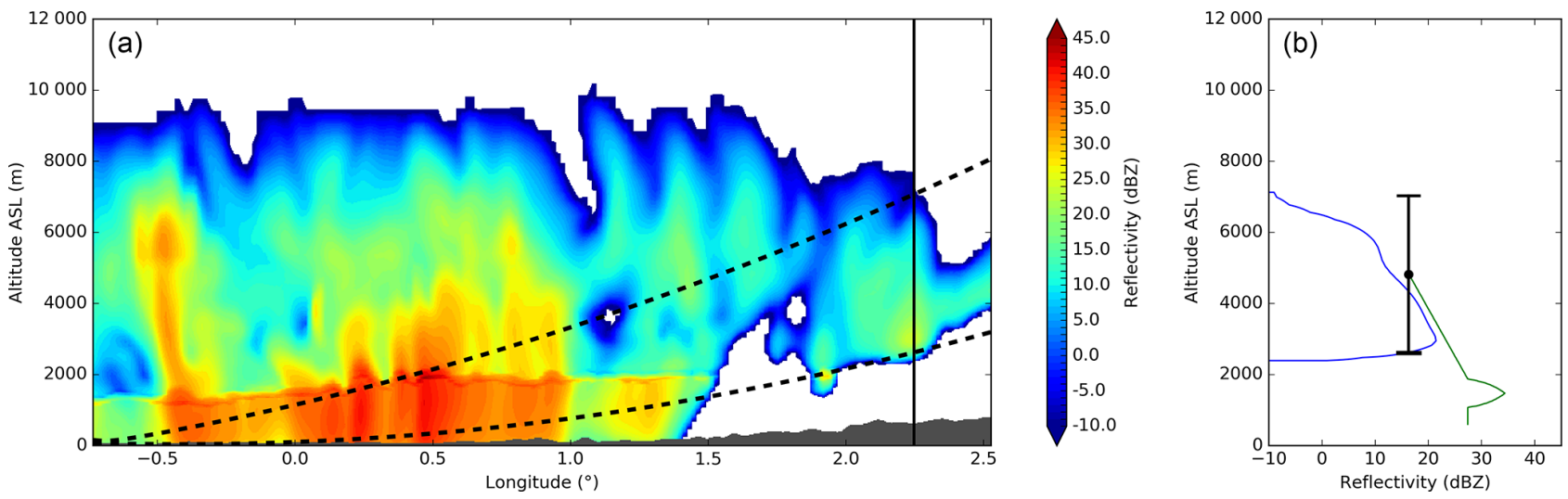

Figure 13. (a) West-to-east cross section of the simulated reflectivity from AROME-NWC (after quantile mapping) of the 3 March 2017 at 21:00 UTC passing by the radar location (situated on the bottom left corner). The radar beam aperture $\left(1.1^{\circ}\right)$ of the lowest elevation $\left(0.4^{\circ}\right)$ is represented by the black dashed lines. (b) Simulated VPR (blue) and extrapolated simulated VPR computed with the operational method from the lowest radar elevation $\left(0.4^{\circ}\right)$ (green) at the location indicated by the vertical black line on the cross section (a). The radar beam aperture $\left(1.1^{\circ}\right)$ of the lowest elevation $\left(0.4^{\circ}\right)$ is represented by the black segment. 
ground from the radar reflectivities aloft. To our knowledge, this is the first time that such a method that combines model outputs and radar observations is used to derive QPEs. The implementation of this method on two stratiform situations (3 March 2017 and 30 April 2018 cases) yielded positive results compared to the current operational system.

In both situations the dramatic biases induced in the operational VPR correction, by either the overestimation of the freezing level altitude or the lack of evaporation or precipitation enhancement below, or both, are largely mitigated in the new method. In both cases, the gains are significant up to maximum range, despite the high altitude of the radar beam. This is very encouraging for the application of the POVPR method in mountainous areas where the radars are most often installed far from the mountains or at high altitude to limit the beam blockages. In addition to this, the use of highresolution NWP models such as AROME-NWC promises to be very helpful for taking into account the high variability of the precipitation that is generally expected over complex terrains. It is indeed reasonable to expect that an NWP model will produce VPR profiles that take into account (i) the orientation of the slopes (windward or leeward) leading to an enhancement or a reduction of the precipitation at the ground, (ii) the strong spatial variability of low level humidity driving the evaporation process and (iii) the higher wind direction and speed variability that causes horizontal displacement of the precipitation as it falls.

This potential for improving QPE in mountainous regions will be evaluated in future work. The robustness of the method will also be tested over longer periods as well as the use of multiple model runs.

Data availability. All the data presented in this study are available from the authors upon request.

Author contributions. All authors contributed to the development of the concept presented in this paper. TLB performed its implementation, conceived the study and prepared the paper with the help of all co-authors.

Competing interests. The authors declare that they have no conflict of interest.

Acknowledgements. The authors wish to thank all members of the Météo-France Radar Centre (CMR) for their help throughout this study, particularly Clotilde Augros for her assistance with the use of the radar forward operator and Jean Millet and Maud Martet for their technical support.

Review statement. This paper was edited by Gianfranco Vulpiani and reviewed by two anonymous referees.

\section{References}

Andrieu, H. and Creutin, J. D.: Identification of vertical profiles of radar reflectivity for hydrological applications using an inverse method, Part I: Formulation, J. Appl. Meteorol., 34, 225-239, 1995.

Auger, L., Dupont, O., Hagelin, S., Brousseau, P., and Brovelli, P.: AROME-NWC: a new nowcasting tool based on an operational mesoscale forecasting system, Q. J. Roy. Meteor. Soc., 141, 1603-1611, 2015.

Augros, C., Caumont, O., Ducrocq, V., Gaussiat, N., and Tabary, P. Comparisons between S-, C-and X-band polarimetric radar observations and convective-scale simulations of the HyMeX first special observing period, Q. J. Roy. Meteor. Soc., 142, 347-362, 2016.

Augros, C., Caumont, O., Ducrocq, V., and Gaussiat, N.: Assimilation of radar dual-polarization observations in the AROME model, Q. J. Roy. Meteor. Soc., 144, 1352-1368, 2018.

Bauer, H.-S., Schwitalla, T., Wulfmeyer, V., Bakhshaii, A., Ehret, U., Neuper, M., and Caumont, O.: Quantitative precipitation estimation based on high-resolution numerical weather prediction and data assimilation with WRF-a performance test, Tellus A, 67, 25047, https://doi.org/10.3402/tellusa.v67.25047, 2015.

Borderies, M., Caumont, O., Augros, C., Bresson, É., Delanoë, J., Ducrocq, V., Fourrié, N., Bastard, T. L., and Nuret, M.: Simulation of W-band radar reflectivity for model validation and data assimilation, Q. J. Roy. Meteor. Soc., 144, 391-403, 2018.

Borderies, M., Caumont, O., Delanoë, J., Ducrocq, V., Fourrié, N., and Marquet, P.: Impact of airborne cloud radar reflectivity data assimilation on kilometre-scale numerical weather prediction analyses and forecasts of heavy precipitation events, Nat. Hazards Earth Syst. Sci., 19, 907-926, https://doi.org/10.5194/nhess19-907-2019, 2019.

Borga, M., Anagnostou, E. N., and Frank, E.: On the use of realtime radar rainfall estimates for flood prediction in mountainous basins, J. Geophys. Res.-Atmos., 105, 2269-2280, 2000.

Bringi, V. N., Keenan, T., and Chandrasekar, V.: Correcting C-band radar reflectivity and differential reflectivity data for rain attenuation: A self-consistent method with constraints, IEEE T. Geosc. Remote, 39, 1906-1915, 2001.

Brousseau, P., Seity, Y., Ricard, D., and Léger, J.: Improvement of the forecast of convective activity from the AROME-France system, Q. J. Roy. Meteor. Soc., 142, 2231-2243, 2016.

Caumont, O., Ducrocq, V., Delrieu, G., Gosset, M., Pinty, J.-P., Parent du Châtelet, J., Andrieu, H., Lemaître, Y., and Scialom, G.: A radar simulator for high-resolution nonhydrostatic models, J. Atmos. Ocean. Technol., 23, 1049-1067, 2006.

Caumont, O., Ducrocq, V., Wattrelot, É., Jaubert, G., and PradierVabre, S.: 1D+3DVar assimilation of radar reflectivity data: A proof of concept, Tellus A, 62, 173-187, 2010.

Creutin, J., Andrieu, H., and Faure, D.: Use of a weather radar for the hydrology of a mountainous area, Part II: radar measurement validation, J. Hydrol., 193, 26-44, 1997.

Dinku, T., Anagnostou, E. N., and Borga, M.: Improving radarbased estimation of rainfall over complex terrain, J. Appl. Meteorol., 41, 1163-1178, 2002.

Figueras i Ventura, J. and Tabary, P.: The new french operational polarimetric radar rainfall rate product, J. Appl. Meteorol. Clim. 52, 1817, https://doi.org/10.1175/JAMC-D-12-0179.1, 2013. 
Figueras i Ventura, J., Boumahmoud, A.-A., Fradon, B., Dupuy, P., and Tabary, P.: Long-term monitoring of French polarimetric radar data quality and evaluation of several polarimetric quantitative precipitation estimators in ideal conditions for operational implementation at C-band, Q. J. Roy. Meteor. Soc., 138, 22122228, 2012.

Georgiou, S., Gaussiat, N., and Lewis, H.: Dynamic modelling of the orographic enhancement of precipitation in the UK, in: Proceedings of the 6th European Conference on Radar in Meteorology and Hydrology, Sibiu, Romania, 2010.

Germann, U. and Joss, J.: Mesobeta profiles to extrapolate radar precipitation measurements above the Alps to the ground level, J. Appl. Meteorol., 41, 542-557, 2002.

Gori, E. and Joss, J.: Changes of shape of raindrop size distributions simultaneously observed along a mountain slope, J. Rech. Atmos, 14, 239-300, 1980.

Gourley, J. J., Illingworth, A. J., and Tabary, P.: Absolute calibration of radar reflectivity using redundancy of the polarization observations and implied constraints on drop shapes, J. Atmos. Ocean. Technol., 26, 689-703, 2009.

$\mathrm{Hu}, \mathrm{Z}$. and Srivastava, R.: Evolution of raindrop size distribution by coalescence, breakup, and evaporation: Theory and observations, J. Atmos. Sci., 52, 1761-1783, 1995.

Joss, J. and Lee, R.: The application of radar-gauge comparisons to operational precipitation profile corrections, J. Appl. Meteorol., 34, 2612-2630, 1995.

Jung, Y., Zhang, G., and Xue, M.: Assimilation of simulated polarimetric radar data for a convective storm using the ensemble Kalman filter, Part I: Observation operators for reflectivity and polarimetric variables, Mon. Weather Rev., 136, 2228-2245, 2008.

Kirstetter, P.-E., Andrieu, H., Delrieu, G., and Boudevillain, B.: Identification of vertical profiles of reflectivity for correction of volumetric radar data using rainfall classification, J. Appl. Meteorol. Clim., 49, 2167-2180, 2010.

Kitchen, M., Brown, R., and Davies, A.: Real-time correction of weather radar data for the effects of bright band, range and orographic growth in widespread precipitation, Q. J. Roy. Meteorol. Soc., 120, 1231-1254, 1994.

Kummerow, C., Olson, W. S., and Giglio, L.: A simplified scheme for obtaining precipitation and vertical hydrometeor profiles from passive microwave sensors, IEEE T. Geosci. Remote, 34, 1213-1232, 1996.

Kummerow, C., Hong, Y., Olson, W., Yang, S., Adler, R., McCollum, J., Ferraro, R., Petty, G., Shin, D.-B., and Wilheit, T.: The evolution of the Goddard Profiling Algorithm (GPROF) for rainfall estimation from passive microwave sensors, J. Appl. Meteorol., 40, 1801-1820, 2001.

Lafon, T., Dadson, S., Buys, G., and Prudhomme, C.: Bias correction of daily precipitation simulated by a regional climate model: a comparison of methods, Int. J. Climatol., 33, 1367-1381, 2013.

Li, X. and Srivastava, R. C.: An analytical solution for raindrop evaporation and its application to radar rainfall measurements, J. Appl. Meteorol., 40, 1607-1616, 2001.

Martinaitis, S. M., Grams, H. M., Langston, C., Zhang, J., and Howard, K.: A Real-Time Evaporation Correction Scheme for Radar-Derived Mosaicked Precipitation Estimations, J. Hydrometeorol., 19, 87-111, 2018.
Mishchenko, M. I., Travis, L. D., and Mackowski, D. W.: T-matrix computations of light scattering by nonspherical particles: a review, J. Quant. Spectrosc. Ra., 55, 535-575, 1996.

Pfeifer, M., Craig, G., Hagen, M., and Keil, C.: A polarimetric radar forward operator for model evaluation, J. Appl. Meteorol. Clim. 47, 3202-3220, 2008.

Purdy, J., Austin, G., Seed, A., and Cluckie, I.: Radar evidence of orographic enhancement due to the seeder feeder mechanism, Meteorological Applications: A journal of forecasting, practical applications, training techniques and modelling, 12, 199-206, 2005.

Ryzhkov, A., Pinsky, M., Pokrovsky, A., and Khain, A.: Polarimetric radar observation operator for a cloud model with spectral microphysics, J. Appl. Meteorol. Clim., 50, 873-894, 2011.

Ryzhkov, A. V., Giangrande, S. E., and Schuur, T. J.: Rainfall estimation with a polarimetric prototype of WSR-88D, J. Appl. Meteorol., 44, 502-515, 2005.

Seity, Y., Brousseau, P., Malardel, S., Hello, G., Bénard, P., Bouttier, F., Lac, C., and Masson, V.: The AROME-France convectivescale operational model, Mon. Weather Rev., 139, 976-991, 2011.

Seo, D.-J., Breidenbach, J., Fulton, R., Miller, D., and O’Bannon, T.: Real-time adjustment of range-dependent biases in WSR-88D rainfall estimates due to nonuniform vertical profile of reflectivity, J. Hydrometeorol., 1, 222-240, 2000.

Smith, P. L.: On the minimum useful elevation angle for weather surveillance radar scans, J. Atmos. Ocean.Technol., 15, 841-843, 1998.

Tabary, P.: The new French operational radar rainfall product, Part I: Methodology, Weather Forecast., 22, 393-408, 2007.

Tabary, P., Guibert, F., Perier, L., and Parent-du Chatelet, J.: An operational triple-PRT Doppler scheme for the French radar network, J. Atmos. Ocean. Technol., 23, 1645-1656, 2006.

Tabary, P., Boumahmoud, A.-A., Andrieu, H., Thompson, R. J., Illingworth, A. J., Le Bouar, E., and Testud, J.: Evaluation of two "integrated" polarimetric Quantitative Precipitation Estimation (QPE) algorithms at C-band, J. Hydrol., 405, 248-260, 2011.

Vignal, B., Andrieu, H., and Creutin, J. D.: Identification of vertical profiles of reflectivity from volume scan radar data, J. Appl. Meteorol., 38, 1214-1228, 1999.

Villarini, G. and Krajewski, W. F.: Review of the different sources of uncertainty in single polarization radar-based estimates of rainfall, Surv. Geophys., 31, 107-129, 2010.

Wolfensberger, D. and Berne, A.: From model to radar variables: a new forward polarimetric radar operator for COSMO, Atmos. Meas. Tech., 11, 3883-3916, https://doi.org/10.5194/amt11-3883-2018, 2018.

Yu, N., Gaussiat, N., and Tabary, P.: Polarimetric X-band weather radars for quantitative precipitation estimation in mountainous regions, Q. J. Roy. Meteorol. Soc., 144, 2603-2619, 2018.

Zawadzki, I.: Factors affecting the precision of radar measurements of rain, in: 22nd conference on radar meteorology, Zurich, Switzerland, 251-256, 1984. 